\title{
A UNIFIED THEORY OF FIRM SELECTION AND GROWTH*
}

\author{
Costas Arkolakis ${ }^{\dagger}$
}

This Version: March, 2015

\begin{abstract}
This paper develops an analytical framework to study firm and exporter growth and provides a dynamic foundation for a standard general equilibrium trade model. Firm-level growth is the result of idiosyncratic productivity improvements and there is continuous arrival of new potential producers. A firm enters a market if it is profitable to incur the marginal cost to reach the first consumer and pays an increasing marketing cost to reach additional consumers. I calibrate the model using data on the cross section of firm sales and bilateral trade, as well as the rate of incumbent firm exit. The calibrated model predicts that a firm's growth is inversely related to its initial size and that the distribution of growth rates of small firms is heavily skewed to the right. These predictions are confirmed by looking at the growth of sales of US firms and Brazilian exporters to the US. I use this model to study the impact of cross-firm reallocations on economic activity and measured productivity. JEL codes: F12, L11, M31, D92.
\end{abstract}

${ }^{*}$ I am grateful to Timothy Kehoe, Samuel Kortum, Cristina Arellano, Jonathan Eaton as well as Giuseppe Moscarini for their insightful comments and discussions on this topic. I am also indebted to Marc Muendler for providing me with moments from the Brazilian data, and Jose Mata for providing me with the estimates for Portuguese firms. For their suggestions and comments, I would also like to thank Andy Atkeson, Evangelia Chalioti, Chang-Tai Hsieh, Myrto Kalouptsidi, Erzo G.J. Luttmer, Anastasios Magdalinos, Ellen McGrattan, Luca Opromolla, Theodore Papageorgiou, Andres Rodriguez-Clare, Esteban Rossi-Hansberg, Larry Samuelson, Adam Slawski, Anthony Tokman, various seminar and conference participants, the referees and the editor. I thank Treb Allen, Olga Timoshenko and especially Xiangliang Li for outstanding research assistance. I gratefully acknowledge the support of the National Science Foundation (under grant SES-0921673) and the CESifo foundation for the CESifo Young Affiliate Prize. All remaining errors are mine. This paper previously circulated under the title "Market Penetration Costs and Trade Dynamics".

†Department of Economics, Yale University, 28 Hillhouse Ave., New Haven, CT, 06511. Email: costas.arkolakis@yale.edu. Online additional material: http://www.econ.yale.edu/ ${ }^{\sim}$ ka265/research.htm 


\section{Introduction}

Small firms play a key role in the growth process of a market economy. They are often carriers of new innovative ideas and the most successful of those quickly become major contributors to economic growth. Policy makers are particularly interested in analyzing the expansion of these firms, which requires the development of an analytical fremework to understand firm growth. ${ }^{1}$ As exporter growth in individual exporting destinations shares similar features to domestic firm growth, such a framework is also important for understanding exporter dynamics. Nevertheless, recent theories of firm growth that rely solely on firm idiosyncratic productivity improvements as a driver of firm dynamics are often at odds with the strong inverse empirical relationship between the growth rate and its variance and initial firm/exporter size. ${ }^{2}$ As such, they are not well equipped to evaluate the importance of small firms in economic growth.

This paper develops a theory of firm selection-entry and exit-and growth that is consistent with empirical evidence on the growth of firms in individual foreign markets and uses it to assess cross-firm reallocations in response to aggregate shocks, such as aggregate technology increases or trade shocks. The key insight is to integrate a model of firm dynamics based on idiosyncratic productivity shocks (Luttmer (2007)) with a theory of demand based on market penetration costs (Arkolakis (2010)). In this combined theory of technology and demand, productivity drives firm growth while market penetration costs introduce important non-homogeneities into this process. Thus, the demand structure implies that improvements in the underlying fundamentals offer asymmetric expansion opportunities to small domestic firms and exporters. ${ }^{3}$ The model generates robust predictions for firm dynamics in each market and can reconcile the inverse empirical relationship between the growth rate and its variance and firm/exporter size.

The new approach offers a unified analytical framework for firm dynamics in the domestic and exporting markets alike and can accommodate a variety of different stochastic processes for firm productivity improvements. The model aggregates to the standard general equilib-

\footnotetext{
${ }^{1}$ For example, the importance of growth of small enterprises is explicitly discussed in the "Integrated Guidelines for Growth and Jobs (2008-2010)", issued by the European Commission. In the United States, the "US Small Business Administration" provides small businesses with contracting, capital and counseling support.

${ }^{2}$ Sutton (1997), Caves (1998), and Sutton (2002), among others, discuss empirical findings on the inverse relationship between the mean and variance of growth rates and initial firm size. Examples of recent theories that rely solely on a technological process to model firm growth are Klette and Kortum (2004), Lentz and Mortensen (2008), and Luttmer (2007).

${ }^{3}$ Unless otherwise noted, I focus on sales at the firm-level, rather than at the plant-level, both for the domestic and foreign markets. This choice allows me to look at rich firm statistics on sales across different destinations and justifies the use of a model with monopolistically competitive firms.
} 
rium multi-market framework of Melitz (2003), consistent with observations on aggregate bilateral trade. In this unified framework, I show that there exists a unique equilibrium under any configuration of trade costs and aggregate technology shocks, so that the model is potentially a useful tool for studying the interactions between aggregate and firm growth.

A firm enters a market only if it finds it profitable to incur the marginal cost to reach the first consumer. Reaching additional consumers in the market requires incurring an increasing marginal market penetration cost. This firm market penetration choice generates an effective demand per market with an elasticity that declines with firm size and asymptotically tends to the Constant Elasticity of Substitution (CES) form. Firm growth is related to this elasticity with the expected growth rate of the largest firms being asymptotically constant. Thus, incorporating market penetration costs is an alternative form of modeling a variable elasticity of demand. This demand specification is widely used in the trade literature. ${ }^{4}$

To keep the analysis tractable I introduce a minimalist setup of firm entry and exit. I assume that new ideas arrive at a constant rate and each one can be used by a monopolistically competitive firm to produce a differentiated good. These ideas become firms only if they are used in production. If not, they enter a mothball state until a future shock to firm productivity makes production profitable. This setup implies that the size of entrants is typically small and roughly equal to the size of exiting firms. Evidence on US manufacturing firms from Dunne, Roberts and Samuelson (1988) and on Brazilian exporters confirms this prediction but is at odds with a setup with sunk costs of entry, which implies that the average size of entrants is larger than that of exiting firms.

In my analysis, I consider as the benchmark case for a stochastic process a geometric Brownian motion with a drift, as in Luttmer (2007), whereby the growth rate of productivities is independent of its level. This specification provides dynamic micro-foundations to the standard distributional assumption of many trade models (Pareto right tails), and allows me to analytically characterize the implications of the model for firm growth. I argue that a fixed cost model combined with firm selection, essentially the Luttmer (2007) setup, is fundamentally inconsistent with the inverse relationship between the mean and variance of growth of firms and their initial size. In that model, surviving firms with small initial size have higher growth rates but a lower variance of growth compared with firms with larger initial size. In the model of endogenous market penetration costs there is a higher variance of the growth rate of small firms due to their market penetration choice. Because of this choice, the model also implies a distribution of growth rates of small firms skewed towards

\footnotetext{
${ }^{4} \mathrm{~A}$ variety of theoretical setups with heterogeneous firms and variable elasticity of demand have recently emerged, following the original contribution of Melitz and Ottaviano (2008). A general demand structure with variable demand elasticity is introduced in Arkolakis et al. (2012).
} 
large growth rates, strikingly different vis-a-vis the fixed cost model. Put differently, the higher elasticity of demand for small firms implies higher variance of growth but also the potential for faster growth.

The model retains the basic structure of a static trade model. This important property allows me to use the wealth of micro-data on exporters to calibrate the benchmark version of the model. I first choose the parameters that affect the static predictions-the parameters that relate to firm demand-using data on the cross-section of firm sales and bilateral trade flows. I then calibrate the drift and the variance of the technological process of firm productivity using the observed rate of exit of incumbent firms, but without using information on firm growth. To do so, I once again exploit the cross-sectional restrictions imposed by the model and the fact that the elasticity of trade in the model is the shape parameter of the (Pareto) size distribution of firm productivities, as in the static model. The latter parameter endogenously arises in the model as a function of the drift and variance of firm productivity.

With this calibration, the model delivers rich dynamic predictions with just one net additional calibrated parameter than its static counterpart. In fact, despite the minimal information on firm exit used for its calibration, the entry-exit process implied by the model accurately predicts the exit rates of both incumbent firms and new entrants in US manufacturing for a time span of two decades. In addition, it predicts the mean growth-size relationship for US firms and Brazilian exporters in the US across different firm percentiles. In both these cases, the fixed cost model falls short of replicating the quantitative evidence. ${ }^{5}$ This success of the endogenous cost model suggests that stylized facts on firm dynamics are intimately linked to the cross-sectional ones, hence the desirability of a "unified" theory of firm selection and growth to analyze firm and exporter growth.

Next, I evaluate the implications of the calibrated model for exporter growth. To this end, I first present novel evidence on the distribution of growth rates for firms of different initial size and age. In particular, I use data on the sales of Brazilian exporters to the US and verify the prediction of the endogenous cost model that the distribution of growth rates is fundamentally different for small versus large exporters: for small exporters it is skewed towards high growth rates, while for large exporters it is roughly shifted lognormal and heavily concentrated around zero growth. In turn, I show that the calibrated endogenous cost model generates such a distribution for different size quartiles. In addition, using the same data, I present the distribution of sizes and growth rates of exporters of different ages. Whereas there is a shift of the distribution of sizes with age, the distribution of growth

\footnotetext{
${ }^{5}$ Impullitti, Irarrazabal and Opromolla (2013) and Atkeson and Burstein (2010) develop two-country extensions of Luttmer (2007). Irarrazabal and Opromolla (2009) adopt a framework of entry and exit similar to the one in this paper. The authors retain the main assumptions of the fixed cost framework and study the theoretically implied entry-exit patterns into individual destinations.
} 
rates remains roughly constant with age. For exporter growth, size appears to play a more prominent role than exporting age.

I use the model to study cross-firm reallocations in the event of a global reduction of trade costs and an aggregate technology shock to the US. In a balanced growth path, the smallest firms grow at a substantially faster pace and retain their market shares despite their large attrition rates, while market shares of the largest firms decline sharply. Instead, a trade liberalization favors the growth of the largest firms at the expense of the others. An increase in US competitiveness benefits all US firms, but especially the smaller ones as a result of large adjustments in their extensive margin of consumers.

This paper follows a large tradition of models of firm dynamics with a continuum of heterogeneous firms. ${ }^{6}$ Behind the main results lies the asymmetry of the growth opportunities for small firms and large firms. Evidence for this violation of Gibrat's law, which states that firm growth rates are independent of size, is cited as justification for differential treatment for small businesses (see for example Birch $(1981,2010)$ ) in an issue that raises attention in both academic and policy circles. The findings of this paper are consistent with empirical findings of the literature that evaluates the importance of small firms and exporters for economic growth, such as Neumark, Wall and Zhang (2011) and Birch (2010) for domestic firms, and Kehoe and Ruhl (2013), Kehoe, Rossbach and Ruhl (2013), Arkolakis (2010) for exports. My findings contradict the conclusions of Davis, Haltiwanger and Schuh (1996) for the importance of small firms for economic growth but the predictions of the model are not inconsistent with their empirical findings. In fact, when I use their empirical specification for calculating firm growth rates in the endogenous cost model, I find that firm growth rate increases in size. This bias in their empirical specification has also been noted by Neumark, Wall and Zhang (2011) and Huber, Oberhofer and Pfaffermayr (2013).

The model also performs well in predicting the size and growth distribution of exporters as a function of their exporting age. Theoretical work on firm learning, as in Jovanovic (1982) and Dunne, Roberts and Samuelson (1989), has created a conventional wisdom that learning can explain firm dynamics, especially the dependence of firm growth on firm age. However, the relationship between firm growth and firm age (or size) depends crucially on the

\footnotetext{
${ }^{6}$ Such models are developed by Hopenhayn (1992), Klette and Kortum (2004), Luttmer (2007) among others. Lentz and Mortensen (2008), Koren and Tenreyro (2013) and Bernard, Redding and Schott (2009) develop models of firm dynamics extending the theories of Klette and Kortum (2004) and Hopenhayn (1992) respectively. In turn, their models inherit many of the qualitative features of these theories. As in the celebrated work of Yule (1925) and Simon (1955), I use the two minimal sufficient conditions of random entry (or exit) and a process that exhibits size independence to generate a cross-sectional distribution with Pareto right tails (Reed (2001)). Random entry is used in lieu of the assumption of a lower exit or reflective barrier and constitutes a major technical simplification compared with prior related work (see for example Luttmer (2007) or Gabaix (1999)).
} 
parametrization of these theories (e.g. demand function, distribution of prior beliefs etc.). This challenging task has only recently started to receive more attention in the literature. ${ }^{7}$

The demand-based explanation of this theory, due to firm market penetration choices, generates predictions that are robust across domestic and exporting markets. It is consistent with the growth patterns of US firms and Brazilian exporters and implies that size-growth relationship is market specific. ${ }^{8}$ These patterns cannot be explained by models with financial constraints (see for example Cooley and Quadrini (2001) and Arellano, Bai and Zhang (2012)) since they imply a relationship of firm growth with overall firm size, and not size in a market. Similarly, Rossi-Hansberg and Wright (2007) and Luttmer (2011) also discuss the alternative explanations of mean reversion in human capital accumulation and an exogenous productivity process for new firms, respectively, but their explanations apply to overall firm size.

The rest of the paper is organized as follows. Section 2 and 3 develop the firm dynamics framework and provide an analytical characterization of its theoretical predictions. Sections 4 and 5 calibrate the model and evaluate its quantitative predictions. Finally, Section 6 concludes.

\section{The Model}

The model introduces market penetration costs, based on the formulation developed by Arkolakis (2010), within a firm dynamics setup, similar to that of Luttmer (2007). I develop a multi-market version of this setup where the decisions of the firms are independent across markets but are connected via the firm's overall productivity level. Thus, the predictions of the model for firm entry-exit and growth apply to the operation of the firm in each market, conditional on its size in that market.

\subsection{Model Setup}

Time is continuous and indexed by $t$. The importing market is denoted by $j$, and the exporting market by $i$, where $i, j=1, \ldots, N$. I assume that each good $\omega$ is produced by a single firm and that each firm reaches consumers independently from other firms. Firms differ ex-ante only in their labor productivity, $z$, and their source market, $i$. In equilibrium, all firms of type $z$ from market $i$ choose to charge the same price in $j, p_{i j t}(z)$, and reach

\footnotetext{
${ }^{7}$ For a related structural approach see Abbring and Campbell (2003) and the more recent work of Eaton et al. (2012), Timoshenko (2012), and Arkolakis, Timoshenko and Papageorgiou (2009).

${ }^{8}$ Foster, Haltiwanger and Syverson (2008) provide evidence on firm growth based on firm demand. The model is also broadly consistent with evidence on the growth of exporters by destination presented by Eaton et al. $(2008,2012)$.
} 
consumers in market $j$ with probability $n_{i j t}(z) \in[0,1]$. Market $j$ is populated by a continuum of consumers of measure $L_{j t}=L_{j} e^{g_{\eta} t}$, where $g_{\eta}$ is the growth rate of the population, $g_{\eta} \geq 0$. At a given date $t$, each consumer $l \in\left[0, L_{j t}\right]$ has access to a potentially different set of goods $\Omega_{j t}^{l}$. The existence of a large number of firms implies that every consumer from $j$ has access to the same distribution of prices for goods of different types. The existence of a large number of consumers in market $j$ implies that the fraction of consumers reached by a firm of type $z$ from $i$ is $n_{i j t}(z)$ and that their total measure is $n_{i j t}(z) L_{j t}$.

Consumers Each consumer from market $j$ has preferences over a consumption stream $\left\{C_{j t}\right\}_{t \geq 0}$ of a composite good from which she derives utility according to

$$
\int_{0}^{+\infty} e^{-\rho t} C_{j t}^{\frac{\iota-1}{t}} d t
$$

where $\rho>0$ is the discount rate and $\iota>0$ is the intertemporal elasticity of substitution. The composite good is made from a continuum of differentiated commodities

$$
C_{j t}=\left(\sum_{i=1}^{N} \int_{0}^{+\infty} c_{i j t}(z)^{(\sigma-1) / \sigma} n_{i j t}(z) d M_{i j t}(z)\right)^{\frac{\sigma}{\sigma-1}},
$$

where $c_{i j t}(z)$ is the consumption of a good produced by a firm $z$ in market $i$ and $\sigma$ is the elasticity of substitution among different varieties of goods where $\sigma>1 . d M_{i j t}(z)$ denotes the density of goods of a given type $z$ from market $i$ that are actually sold to $j$, i.e., the probability density of type $z$ goods from $i$, conditional on being sold in $j$, multiplied by their total measure. Because all consumers from market $j$ have access to the same distribution of prices, their level of consumption $C_{j t}$ is the same.

Each household earns labor income $w_{j t}$ from selling its unit labor endowment in the labor market and profits $\pi_{j t}$ from the ownership of domestic firms. Thus, the demand for good $z$ from $i$ by a consumer from market $j$ is

$$
c_{i j t}(z)=\frac{p_{i j t}(z)^{-\sigma}}{P_{j t}^{1-\sigma}} y_{j t},
$$

with income per capita given by

$$
y_{j t}=w_{j t}+\pi_{j t}
$$

and

$$
P_{j t}^{1-\sigma}=\sum_{v=1}^{N} \int_{0}^{+\infty} p_{v j t}(z)^{1-\sigma} n_{v j t}(z) d M_{v j t}(z) .
$$

Given the definition of the price index, $P_{j t}$, the budget constraint faced by each consumer is 
$C_{j t} P_{j t}=y_{j t}$. Thus, the total effective demand in market $j$ for a firm of type $z$ from $i$ is

$$
q_{i j t}(z)=n_{i j t}(z) L_{j t} \frac{p_{i j t}(z)^{-\sigma}}{P_{j t}^{1-\sigma}} y_{j t}
$$

Firms Firms can produce in each period for any of their markets using a standard constant returns to scale production function $q(z)=z l$, where $l$ is the amount of labor used in production and $z$ is the labor productivity of the idea at a given date. The dynamic evolution of productivities that determines the value of $z$ for each firm at each data will be discussed in the next subsection. Firms face demand (3) and, to sell in a given market, pay a market penetration cost, which is a function of the number of consumers reached in that market. I model these market penetration costs by using the formulation of Arkolakis (2010), derived from a technology of marketing. I assume that these costs are incurred by the firms continuously, analogous to the models of Melitz (2003) and Luttmer (2007), in which a per market fixed cost is required for the firm to operate at each instant. ${ }^{9}$ This formulation of the marketing cost function introduces an asymmetry into the growth opportunities of small and large firms.

The labor required for a firm to reach a fraction of consumers $n$ in a market of population size $L$ is

$$
F(n, L)= \begin{cases}\frac{L^{\alpha}}{\psi} \frac{1-(1-n)^{-\beta+1}}{-\beta+1} & \text { if } \beta \geq 0, \beta \neq 1 \\ -\frac{L^{\alpha}}{\psi} \log (1-n) & \text { if } \beta=1\end{cases}
$$

where $\alpha \in[0,1]$ and $\psi>0$. If $\alpha<1$, the market penetration costs to reach a certain number of consumers decrease with the population size of the market. The parameter $\beta$ governs the convexity of the market penetration cost function: higher $\beta$ implies more convexity and steeper increases in the marginal cost to reach more consumers. I assume that labor from the home market is hired for marketing purposes. This specification implies that the total market penetration cost paid by a firm from $i$ that reaches a fraction $n$ of consumers in market $j$ is $w_{i} F\left(n, L_{j}\right)$.

In addition to the cost to reach consumers, the firm has to pay a variable trade cost at each time $t$ modeled through the use of the standard iceberg formulation. This iceberg cost implies that a firm operating in $i$ and selling to market $j$ must ship $\tau_{i j t}>1$ units for one unit of the good to arrive at the destination, where I set $\tau_{j j t}=1$ for all $j, t$.

\footnotetext{
${ }^{9}$ This formulation of marketing costs is based on ample evidence that marketing efficiency declines as marketing expenditure increases and lends itself to a variety of isomorphic interpretations, as discussed in Arkolakis (2010). My modeling of marketing is static, which enables me to analytically characterize the various properties of the model. A model that examines state dependence of market penetration costs on previous marketing decisions (marketing capital) is left for future research.
} 


\subsection{Dynamic Evolution of Firms and Ideas}

An "idea" is a way to produce a unique good $\omega$. Each idea is exclusively owned and grants a monopoly in production over the related good. This exclusivity implies a monopolistic competition setup as in Dixit and Stiglitz (1977) and Melitz (2003). In my context, a firm is an idea put to work to produce and market a good. If an idea is not put to work, it enters a mothball state until a future shock in productivity makes production profitable.

To obtain a simple characterization of the cross-sectional distribution of the productivities of ideas and firms I assume a constant population growth rate, $g_{\eta}$, I also need to introduce two more constant growth rates: the rate of innovation, $g_{B}$, and the rate of increase of the "quality" of new ideas $g_{E}$. In particular, each market innovates at an exogenous rate $g_{B} \geq 0$ so that the measure of existing ideas at time $t$ in $i$ is $J_{i t}=J_{i} e^{g_{B} t}$, where $J_{i}>0$ is the initial measure of ideas in $i$. New ideas arrive with the initial quality $\bar{z}_{i, t^{b}}$, given by

$$
\bar{z}_{i, t^{b}}=\bar{z}_{i} e^{g_{E} t^{b}}
$$

where $\bar{z}_{i}, g_{E}>0$. The parameter $g_{E}$ indicates the growth rate of the quality of new ideas and all new ideas at time $t$ enter with the same productivity. This specification incorporates a form of "creative destruction" as more recent ideas arrive with a higher quality. ${ }^{10}$

The productivity of an idea born at time $t^{b}$ depends on its initial quality, $\bar{z}_{i t^{b}}$, and evolves with age $a$ according to

$$
z_{i t^{b}, a}=A_{i t} \tilde{z}_{a} e^{g_{I} a} \bar{z}_{i t^{b}}, t=t^{b}+a,
$$

where $g_{I}$ is a constant rate of improvement, $A_{i t}$ is a country-specific aggregate technology shock, as in Fujii (2013), and $\ln \tilde{z}_{a}$ evolves according to a standard Ito diffusion process

$$
\operatorname{dln} \tilde{z}_{a}=g\left(\tilde{z}_{a}\right) d a+\sigma\left(\tilde{z}_{a^{\prime}}\right) d W_{a}
$$

where $W_{a} \sim \mathcal{N}(0, a)$ is a standard Brownian motion with independent increments. The function $g(z)$ affects the rate at which the productivity of incumbent ideas improves, on average, and $\sigma(z)$ affects their volatility. Both can depend on the current productivity level of the idea.

Equation (5) generalizes previous processes considered in the literature. In particular, if

$$
g(z)=0, \sigma(z)=\sigma_{I},
$$

\footnotetext{
${ }^{10}$ Extending this simple case to one in which new entrants arrive with different productivities drawn from a non-atomic distribution is straightforward (see, for example, Reed (2002)). In particular, unless entrants are specified to be very large with a high probability, the right tails of the distribution will be unaffected.
} 
the rate at which idiosyncratic productivities improve is $g_{I}$; i.e., the productivity of ideas follows a geometric Brownian motion as in Luttmer (2007), and their expected growth is independent of size. Similar processes have been widely used to represent firm growth since Gibrat (1931). To allow the growth of productivities to depend on size and age, I also consider a standard Ornstein-Uhlenbeck (O-U) process, adjusted for productivity growth, which simply requires specifying

$$
g(z)=-\rho \ln z, \sigma(z)=\sigma_{I}, \rho \geq 0
$$

This process exhibits mean reversion when $\rho>0$, where age dependence arises because different cohorts have different levels of productivity at entry. As discussed in the Appendix, the $\mathrm{O}-\mathrm{U}$ process is the continuous time analog of an $\mathrm{AR}(1)$ process where the autoregressive coefficient is equal to $e^{-\rho}$. The $\mathrm{AR}(1)$ process has also been used widely to represent firm growth (see Hopenhayn and Rogerson (1993), Rossi-Hansberg and Wright (2007), Alessandria and Choi (2007), among others). While both parametrizations have a discrete time analog, the assumption of continuous time is convenient for solving and analytically characterizing the model. I can now proceed to characterize the optimal decisions of the firms and the equilibrium of the model.

\section{$2.3 \quad$ Firm Optimization}

Given the constant returns to scale production technology and the separability of the market penetration cost function across markets, the decision of a firm to sell to a given market is independent of the decision to sell to other markets. Total profits of a particular firm are the summation of the profits from exporting activities in any market $j=1, \ldots, N$. Thus, at a given time $t$, the firm's problem is the same as that in Arkolakis (2010). The current level of productivity $z$ of a firm from $i$ is the only state variable since it solves the following static maximization problem for each given market $j$ :

$$
\begin{aligned}
\pi_{i j t}(z)= & \max _{n_{i j t}, p_{i j t}}\left\{n_{i j t} L_{j t} y_{j t} \frac{p_{i j t}^{1-\sigma}}{P_{j t}^{1-\sigma}}-n_{i j t} L_{j t} y_{j t} \frac{\tau_{i j t} p_{i j t}^{-\sigma} w_{i t}}{P_{j t}^{1-\sigma} z}-w_{i t} \frac{L_{j t}^{\alpha}}{\psi} \frac{1-\left[1-n_{i j t}\right]^{-\beta+1}}{-\beta+1}\right\} \\
& \text { s.t. } n_{i j t} \in[0,1] \forall t .
\end{aligned}
$$

For any $\beta$, the optimal decisions of the firm in the multi-market model are:

$$
p_{i j t}(z)=\tilde{\sigma} \frac{\tau_{i j t} w_{i t}}{z}
$$


where $\tilde{\sigma}=\sigma /(\sigma-1)$, and

$$
n_{i j t}(z)=\max \left\{1-\left(z_{i j t}^{*} / z\right)^{(\sigma-1) / \beta}, 0\right\}
$$

The cutoff productivity, $z_{i j t}^{*}$, is implicitly defined by the solution of $\pi_{i j t}(z)=0$ and thus

$$
z_{i j t}^{*}=\left[L_{j t}^{1-\alpha} y_{j t} w_{i t}^{-1}\left(\tilde{\sigma} \tau_{i j t} w_{i t}\right)^{1-\sigma} \psi P_{j t}^{\sigma-1} / \sigma\right]^{-1 /(\sigma-1)}
$$

Equation (10) reveals that, apart from general equilibrium considerations, the cutoff productivity, and, thus, the entry-exit decision of the firm do not depend on the parameter $\beta$. Intuitively, $\beta$ regulates the convexity of market penetration costs but not the level of the cost to reach the very first consumer.

Because there is no indivisible cost of production or entry, ideas with productivity higher than $z_{i j t}^{*}$ are used in production and appear as firms in market $j .{ }^{11}$ This setup for entry and exit makes the model substantially more tractable than that of Luttmer (2007), as there are no forward looking decisions for the firms. Additionally, it captures the possibility that a firm may temporarily shut down as discussed in Lee and Mukoyama (2008). These temporary shutdowns may appear, for example, because of plant retooling. Reliable information on temporary shutdowns of domestic firms is scarce but the phenomenon of temporary exit in the exporting data is prevalent as discussed in Section 4.

Substituting (8), (9) and (10) into the expression for sales per firm, equation (3), and multiplying it by the price, equation (8), the sales of firm $z$ that originate from market $i$ in market $j$ can be written as a function of the relative efficiency $z / z_{i j t}^{*}$,

$$
r_{i j t}(z) \equiv p_{i j t}(z) q_{i j t}(z)= \begin{cases}L_{j t}^{\alpha} w_{i t} \frac{\sigma}{\psi}\left[e^{\bar{c}_{1} \ln \left(z / z_{i j t}^{*}\right)}-e^{\bar{c}_{2} \ln \left(z / z_{i j t}^{*}\right)}\right] & \text { if } z \geq z_{i j t}^{*} \\ 0 & \text { otherwise }\end{cases}
$$

where

$$
\bar{c}_{1}=\sigma-1, \bar{c}_{2}=(\sigma-1) \frac{(\beta-1)}{\beta} .
$$

Equation (11) reveals that for $\beta \rightarrow 0$ all firms that sell from $i$ to $j$ sell at least a minimum amount, $\sigma L_{j t}^{\alpha} w_{j t} / \psi$, while for $\beta>0$ this amount is 0 . Conditional on entry, more productive firms have higher sales as equation (11) indicates. These firms charge lower prices and thus sell more per consumer (i.e., the intensive margin). In addition, if $\beta>0$, they also reach

\footnotetext{
${ }^{11}$ In the one market model, allowing for free entry of ideas with a fixed amount of labor used for each new idea would imply a setup with identical predictions. Differences arise only because profits accrue to labor used for the entry cost, as in Arkolakis et al. (2008). However, such an extension is analytically intractable within a multi-market framework, given that operation into multiple markets affects expected profits.
} 
more consumers (i.e., extensive margin), as implied by equation (9). However, if $\beta \rightarrow 0$, all entrants in market $j$ optimally choose $n_{i j}=1$. These differences in $\beta$ are reflected in firm growth-patterns as I illustrate in Section 3.

\subsection{Productivity Distribution and Equilibrium}

Under very weak conditions over functions $g(z)$ and $\sigma(z)$, the dynamic evolution of ideas gives rise to an absolutely continuous (with respect to the Lebesgue measure) distribution of productivities for each cohort; i.e., there exists a probability density function (pdf) $f_{i}(z, a)$. As is shown in Proposition 1, Assumption A1 guarantees that $f_{i}(z, a)$ is well defined.

Assumption 1 (A1). The functions $g(z), \sigma(z)$ satisfy $\sigma^{2}(z)+\left[g(z) \sigma^{\prime}(z)\right]^{2} \neq 0$ for all $z$.

This condition is the equivalent of Hormander's condition for Ito diffusions (see Nualart (2006), page 111) and is satisfied by specifications (6) and (7) for $\sigma_{I}>0$. The intuition for this assumption is straightforward: to guarantee the distribution is absolutely continuous-to avoid a mass point-the stochastic process has to either continuously diffuse $(\sigma(z) \neq 0)$ or move to a location that will diffuse $\left(g(x) \sigma^{\prime}(x) \neq 0\right)$.

Furthermore, pooling ideas of all cohorts together correspondingly gives rise to a distribution of productivity across all cohorts with pdf

$$
f_{i}(z)=\int_{0}^{+\infty} g_{B} e^{-g_{B} a} f_{i}(z, a) d a
$$

To guarantee the existence of $f_{i}(z)$, I assume that there is a constant flow of new ideas:

Assumption 2 (A2). The rate of innovation is positive, $g_{B}>0$.

The following proposition establishes the existence of a pdf for the distribution of ideas.

Proposition 1. Consider the process (5).

$i$. Suppose A1 holds. Then there exists a pdf, $f_{i}(z, a)$, for each cohort a.

ii. Suppose A1-A2 hold. Then there exists a pdf, $f_{i}(z)$, which is finite almost everywhere.

Proof. The proof is provided in Appendix B.

Note that in the proof it is also shown that if all the derivatives of $g(z)$ and $\sigma(z)$ are bounded then $f_{i}(z, a)$ is infinitely differentiable on $z$ and continuous on $a$.

I now turn to discuss the conditions that characterize the general equilibrium of the model. Given the stationary pdf, $f_{i}(z)$, the equilibrium is characterized by labor market 
clearing, which is equivalent to guaranteeing that total income is equal to the value of goods sold to all destinations,

$$
\left(w_{i t}+\pi_{i t}\right) L_{i t}=\sum_{j} \lambda_{i j t}\left(w_{j t}+\pi_{j t}\right) L_{j t}
$$

where

$\pi_{i t} L_{i t}=\sum_{v} J_{v} \int_{z_{v j t}^{*}} \pi_{v j t}(z) f_{v}(z) d z=\sum_{v} J_{v} \int_{z_{v j t}^{*}}\left[r_{v j t}(z) / \sigma-w_{i t} F\left(n_{v j t}(z), L_{j t}\right)\right] f_{v}(z) d z$

and the cutoff $z_{i j t}^{*}$ is defined in (10) as a function of per capita income, $y_{i t}$, and wage, $w_{i t}$, and

$$
\lambda_{i j t} \equiv \frac{J_{i} \int_{z_{i j t}^{*}} r_{i j t}(z) f_{i}(z) d z}{\sum_{v} J_{v} \int_{z_{v j t}^{*}} r_{v j t}(z) f_{v}(z) d z} .
$$

In addition, the representative consumer's budget balances every period, and thus the per capita income in country $i$ is given by equation (1). To summarize, an equilibrium is wages, $w_{i t}$, income per capita, $y_{i t}$, bilateral cutoffs, $z_{i j t}^{*}$, such that (1), (13), and (10) are satisfied for all $t$. The next proposition establishes the existence and uniqueness of an equilibrium at each time $t$.

Proposition 2. Suppose that A1-A2 hold, $\int_{z^{*}}^{\infty} e^{\bar{c}_{1} \ln \left(z / z^{*}\right)} f(z) d z$ is finite for any $z^{*}>0$ and $f_{i}(z)>0$. Then there exists a unique equilibrium for all $t$.

Proof: The proof is based on the methodology of Allen, Arkolakis and Li (2014). See the online appendix.

A few points are in order. First, by focusing on distributions with positive density on the entire positive domain a number of distributions can be accommodated, such as the Frechet, lognormal, and double Pareto, which is introduced below. It is also possible to appropriately modify distributions that do not have positive density in the entire positive domain, such as the simple Pareto distribution (see for example, Eaton and Kortum (2011), chapter 4). Second, $\sigma(z)>0$ guarantees that the resulting density from the stochastic process (5) is positive everywhere. Third, the requirement of the proposition for a finite integral guarantees that all relevant economic magnitudes (all aggregate bilateral trade flows) are finite in this model. It is satisfied by imposing different constraints for different pdfs, $f_{i}(z)$, and I do so for the two examples that I consider.

Using numerical tools, the equilibrium of the model can be computed for any distribution $f_{i}(z)$ and any $A_{i t}$ and $\tau_{i j t}$. A case that is particularly amenable to analytical characterization is a balanced growth path, which I discuss below. 


\subsection{Balanced Growth and the Cross-section of Firms}

To construct a balanced growth path I consider as a benchmark specification (6). Under this formulation the model yields a closed form solution and firm dynamics are rich but very easy to characterize. To proceed, note that because of expression (11) firm sales are determined by the ratio of firm productivity to the cutoff productivity, $z / z_{i j t}^{*}$. In the balanced growth path $z_{i j t}^{*}$ will be shown to grow at a constant rate: the sum of the rate of increase of the quality of new ideas and the rate of growth of aggregate technology. It is therefore convenient to first characterize the distribution of productivities de-trended by the rate of growth of the productivity of new ideas and the aggregate technological growth,

$$
z_{t^{b}, a} /\left[A_{i t} \exp \left\{g_{E}\left(t^{b}+a\right)\right\}\right]=\bar{z}_{i} \exp \left\{\left(g_{I}-g_{E}\right) a+\sigma_{I} W_{a}\right\}
$$

since this ratio will be proportional to $z / z_{i j t}^{*}$ in the balanced growth path. Without the risk of confusion I maintain the notation $z$ for the de-trended productivities, and I define the term $\mu \equiv g_{I}-g_{E}$, the difference in the mean growth of the productivity of incumbent and new ideas.

The logarithm of normalized productivities for a given generation of ideas of age $a>0$ from $i$ follow a normal distribution: ${ }^{12}$

$$
f_{i}(z, a)=\frac{1}{\sigma_{I} \sqrt{a 2 \pi}} \exp \left\{-\left(\frac{\ln z-\ln \bar{z}_{i}-\mu a}{\sigma_{I} \sqrt{a}}\right)^{2} / 2\right\} .
$$

This distribution implies that the model matches the findings of Cabral and Mata (2003) that the size distribution of old firms converges to a lognormal distribution.

The resulting cross-sectional distribution of de-trended productivities $z \in(0,+\infty)$ is the so-called double Pareto distribution (Reed (2001)) with probability density function: ${ }^{13}$

$$
f_{i}(z)=\left\{\begin{array}{c}
\frac{\theta_{1} \theta_{2}}{\theta_{1}+\theta_{2}} \frac{z^{\theta_{1}-1}}{\bar{z}_{i}^{\theta_{1}}} \text { if } z<\bar{z}_{i} \\
\frac{\theta_{1} \theta_{2}}{\theta_{1}+\theta_{2}} \frac{z^{-\theta_{2}-1}}{\bar{z}_{i}^{-\theta_{2}}} \text { if } z \geq \bar{z}_{i}
\end{array}\right.
$$

\footnotetext{
${ }^{12}$ See for example Harrison (1985) (page 37). $f_{i}(s, a)$ can be derived as the solution of the differential equation $D_{a} f_{i}(s, a)=-\mu D_{s}\left(s f_{i}(s, a)\right)+\frac{1}{2} \sigma_{I}^{2} D_{s s}\left(s^{2} f_{i}(s, a)\right)$ with initial condition $f_{i}(s, a)=\Delta\left(s-\bar{s}_{i}\right)$, where $\Delta($.$) is the Dirac delta function.$

${ }^{13}$ Under the assumption $\mu>0$, a Pareto distribution emerges in the right tail of the distribution for the limit case of $\sigma_{I} \rightarrow 0$.
} 
Figure I: Double Pareto distribution

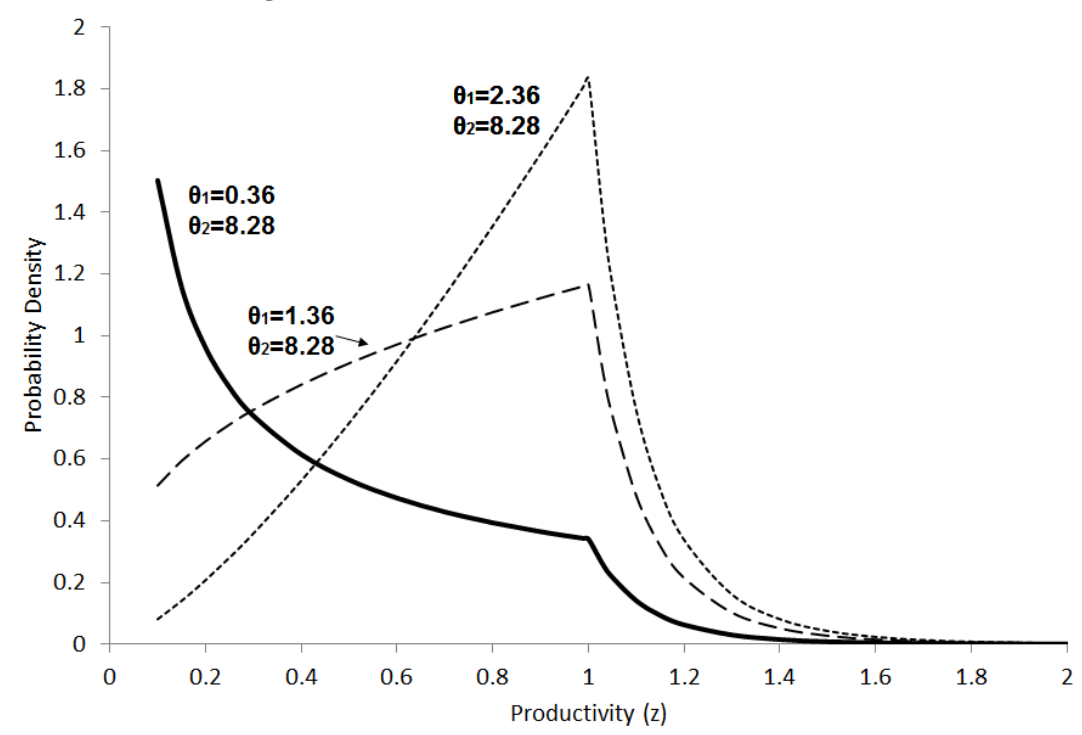

Note: The Double Pareto Distribution for different parameters. The combination $\theta_{1}=0.36, \theta_{2}=8.28$ arises from the benchmark calibration in Section 4.

where $^{14}$

$$
\begin{gathered}
\theta_{1}=\frac{\mu+\sqrt{\mu^{2}+2 \sigma_{I}^{2} g_{B}}}{\sigma_{I}^{2}}>0, \\
\theta_{2}=-\frac{\mu-\sqrt{\mu^{2}+2 \sigma_{I}^{2} g_{B}}}{\sigma_{I}^{2}}>0 .
\end{gathered}
$$

The double Pareto distribution is illustrated in Figure I for different parameter values of $\theta_{1}$. The parameter $\theta_{2}$ affects the right tail of the distribution and will be pinned down in the calibration. A closer look at the probability density of productivities (equation 16) reveals that, at each date, a constant fraction of ideas $\theta_{1} /\left(\theta_{1}+\theta_{2}\right)$ is above the threshold $\bar{z}_{i}$. To keep all the expressions of the model simple I assume for the rest of the paper that $1 / \psi$ is sufficiently high so that $z_{i j t}^{*}>\bar{z}_{i t}, \forall i, j, t{ }^{15}$ In that case, the (de-trended) crosssectional distribution of operating ideas (i.e., firms) in each market $j$ is Pareto with shape parameter $\theta_{2}$. This result provides a dynamic foundation for the assumption of the Pareto distribution postulated in many static trade models (see e.g. Helpman, Melitz and Yeaple (2004), Chaney (2008), and Arkolakis, Costinot and Rodríguez-Clare (2012)). Thus, as in

\footnotetext{
${ }^{14}$ In the online appendix, I provide a proof by explicitly calculating (12). The proof, while straightforward, provides little insight on the forces that form $f_{i}(z)$. Reed (2001) provides another proof that uses moment generating functions in which the intuition is also somewhat limited.

${ }^{15}$ With an aggregate technology shock and an infinite time horizon the inequality may not hold for some periods. Since the instance of this happening is small, if the initial $\bar{z}_{i t}$ is sufficiently low, I assume that the inequality holds throughout the rest of the text.
} 
these models, the shape parameter $\theta_{2}$ maintains the role of a "trade elasticity" that regulates the responsiveness of bilateral trade flows to changes in the bilateral iceberg costs (while all the relevant equilibrium objects do not vary with $\theta_{1}$ ).

To shed insight on the exact forces that give rise to the shape of the cross-sectional distribution of productivities note that, with entry and exit of ideas, the dynamics of the probability density of each $z \neq \bar{z}_{i}$ and $\forall i$ are described by a Kolmogorov forward equation,

$$
-\frac{\partial}{\partial z}\left[\mu z f_{i}(z)\right]+\frac{1}{2} \frac{\partial^{2}}{\partial z^{2}}\left[\sigma_{I}^{2} z^{2} f_{i}(z)\right]-g_{B} f_{i}(z)=0
$$

In a stationary steady state, at each $z \in\left(0, \bar{z}_{i}\right) \cup\left(\bar{z}_{i},+\infty\right)$ the net changes in the distribution due to the stochastic evolution of the productivities (the first two terms) must equal the rate of reduction of the probability density due to new innovation (the third term).

The pdf must also satisfy the standard requirements ${ }^{16}$

$$
f_{i}(z) \geq 0, \forall z \in(0,+\infty)
$$

and

$$
\int_{-\infty}^{\bar{z}_{i}} f_{i}(z) d s+\int_{\bar{z}_{i}}^{+\infty} f_{i}(z) d s=1
$$

Finally, net inflows into the distribution must equal the net outflows: ${ }^{17}$

$$
-\mu\left[\bar{z}_{i} f_{i}\left(\bar{z}_{i}-\right)-\bar{z}_{i} f_{i}\left(\bar{z}_{i}+\right)\right]+\frac{1}{2} \sigma_{I}^{2}\left[\frac{\partial}{\partial \bar{z}_{i}}\left(\bar{z}_{i} f_{i}\left(\bar{z}_{i}-\right)\right)-\frac{\partial}{\partial \bar{z}_{i}}\left(\bar{z}_{i} f_{i}\left(\bar{z}_{i}+\right)\right)\right]=g_{B}
$$

The left-hand side is the net inflows into the distribution from point $\bar{z}_{i}$. The right-hand side is the outflows from the distribution due to new entry and random exit of ideas. By continuity, the first bracketed term is zero. However, entry of new ideas implies that the distribution is kinked at $\bar{s}_{i}$. Intuitively, the rate of change of the pdf changes direction at $\bar{z}_{i}$ because entry happens at that point. The proof that the density in (16) is the solution of the equation (19) subject to (20), (21) and (22) is provided in Appendix B.3.

\footnotetext{
${ }^{16}$ The resulting distribution can be thought of as a limit case of the distribution of firms derived by Luttmer (2007) when the exit cutoff in that model goes to 0 . However, in this case, this assumption would imply that firms never exit and that there is no selection in that model.

${ }^{17}$ With $f_{i}\left(\bar{z}_{i}-\right)$ and $f_{i}\left(\bar{z}_{i}+\right)$ I denote the right- and the left-limit of the distribution, respectively. This condition results by integrating (19) over all $z \in\left(-\infty, \bar{z}_{i}\right) \cup\left(\bar{z}_{i},+\infty\right)$, i.e., by considering the net inflows from point $\bar{s}_{i}$ to the rest of the distribution. Similar conditions are used in labor models to characterize the behavior of the distribution at a point of entry to or exit from a particular occupation (see for example Moscarini (2005) and Papageorgiou (2014)).
} 
Using equation (18), A2 also implies that

$$
\theta_{2} \mu+\left(\theta_{2}\right)^{2} \sigma_{I}^{2} / 2=g_{B}>0
$$

Given A1, A2 is necessary for a stationary distribution. An additional assumption guarantees that the resulting distributions of firm productivity and sales have a finite mean satisfying the final requirement of Proposition 2:

Assumption 3 (A3). Productivity and sales parameters satisfy

$$
g_{B}>\max \left\{\mu+\sigma_{I}^{2} / 2,(\sigma-1) \mu+(\sigma-1)^{2} \sigma_{I}^{2} / 2\right\}
$$

A3 ensures that the entry rate of new ideas is larger than the growth rate of an incumbent's productivity and sales of the largest incumbent firms. Notice that A2 and A3 also imply the common restriction that the Pareto shape coefficient, $\theta_{2}$, is larger than both 1 and $\sigma-1$ (see equation 23). Therefore, A2-A3 imply a set of restrictions between $\mu, \sigma_{I}, \sigma$ and $g_{B}$, not necessarily independent from one another.

Since the cross-sectional distribution of the productivities of operating firms is Pareto, aggregation is straightforward. For each cross section of the model, the share of profits in total income is constant and equals $\bar{\pi}=(\sigma-1) /\left(\sigma \theta_{2}\right)$ (see Arkolakis (2010)). Thus, given equation (1), equation (13) can be expressed as a function of wages alone where the market share from $i$ to $j$ equals to

$$
\lambda_{i j t}=\frac{\left(\tau_{i j t}\right)^{-\theta_{2}} J_{i}\left(\bar{z}_{i} A_{i t}\right)^{\theta_{2}} w_{v t}^{-\theta_{2}-\tilde{\theta}+1}}{\sum_{v=1}^{N}\left(\tau_{v j t}\right)^{-\theta_{2}} J_{v}\left(\bar{z}_{v} A_{v t}\right)^{\theta_{2}} w_{v t}^{-\theta_{2}-\tilde{\theta}+1}}
$$

where $\tilde{\theta} \equiv \theta_{2} /(\sigma-1)$.

In order to obtain insights for the main predictions of the model I construct a balanced growth path. This requires the growth rate of productivities and the trade costs to be constant:

Assumption 4 (A4). The growth rate of aggregate technology, $g_{A} \geq 0$, is constant across countries and time, and trade costs are constant across time $\tau_{i j t}=\tau_{i j}$.

In addition, I specify the entry rate of new ideas to be

$$
g_{B}=g_{\eta}(1-\alpha)
$$


implying that the number of ideas above the entry point will be $\theta_{1} /\left(\theta_{1}+\theta_{2}\right) J_{i} e^{g_{\eta}(1-\alpha) t} .^{18}$ In the balanced growth path, per capita aggregate variables, $w_{i t}, C_{i t}$, grow at a rate $g_{\kappa}$ where ${ }^{19}$

$$
g_{\kappa}=g_{E}+g_{A}+g_{\eta}(1-\alpha) /(\sigma-1)
$$

The entry rate of new ideas affects growth more when goods are less substitutable. ${ }^{20}$ Given these restrictions all the aggregate variables grow at a constant-but possibly different-rate and trade shares are constant.

Proposition 3. Suppose that A2-A4 hold, and the values of $g_{B}, g_{\kappa}$, are given by (25) and (26), respectively. There exists a balanced growth path for the economy where all aggregate variables grow at a constant rate.

Proof. By assumption, $L_{i t}=L_{i} e^{g_{\eta} t}$ and $J_{i t}=J_{i} e^{g_{\eta}(1-\alpha) t}$, and $\bar{z}_{i t}=\bar{z}_{i} \exp \left(g_{E} t\right)$. Define $z_{i j t}^{*}=z_{i j}^{*} e^{\left(g_{E}+g_{A}\right) t}$, such that $z_{i j}^{*}>\bar{z}_{i}, w_{i t}=w_{i} e^{g_{\kappa} t}, C_{i t}=C_{i} e^{g_{\kappa} t}$, and $P_{i t}=P_{i}$. The equilibrium wages are solved using (13) and (24), the price index given by (2), and the cutoff productivity condition given by (10). Simply substituting the values of the variables into these equilibrium equations reveals that the equations hold for all $t$ and allows to solve for the values of $z_{i j}^{*}, w_{i}, P_{i}$. Finally, $C_{i}$ can be solved using the budget constraint.

Moreover, I will typically restrict the analysis to parameter values that will allow me to match the facts on firm growth rates as a function of firm size. Although not necessary for the existence of a balanced growth path, the following restriction implies that there is positive growth, on average, in the extensive margin of consumers for the smaller firms.

Restriction 1 (R1). Productivity and sales parameters satisfy $\mu+\sigma_{I}^{2}(\sigma-1)>0$.

This restriction will be satisfied by the calibrated parameters.

\footnotetext{
${ }^{18}$ The model can be enriched by assuming that there is an exogenous exit of firms at a rate $\delta$. This exit would play the same role in shaping the productivity distribution as does the entry of new ideas. To be consistent with the balanced growth path the rate of innovation has to be defined as $g_{B}=g_{\eta}(1-\alpha)+\delta$.

${ }^{19}$ Other balanced growth paths can be constructed by picking different growth rates of $g_{B}$. For example, if I assume that $g_{B}=g_{\eta}$ the growth rate of per capita aggregate variables will also be a function of $\theta_{2}$, as long as $\alpha>0$.

${ }^{20}$ The equilibrium also requires that the value of the aggregate endowment is finite. For this to happen, the discount rate must exceed the rate of growth of the economy and, thus, preference and technology parameters must satisfy $\rho+\frac{1}{\iota} g_{\kappa}>g_{\kappa}+g_{\eta}$. This restriction and, in particular, the values of the parameters $\rho$ and $\iota$ play no essential role in my analysis and will not be discussed in what follows.
} 


\section{Balanced Growth Path and Firm Dynamics}

I now describe the theoretical properties of the model and present the connection to empirical findings. Details of the various derivations in this section are in Appendix B. The productivity of an idea can be considered at a given time $\tilde{t}$ as a new process starting from current productivity $z_{\tilde{t}}$. For convenience, I define a proxy of the relative "size" of an idea from a given origin $i$ to a given destination $j$ when $a$ years have elapsed from some reference time $\tilde{t}$, relative to other ideas active in that destination, as summarized by the cutoff productivity $z_{i j \tilde{t}+a}^{*}$

$$
s_{i j a} \equiv \ln \left(z_{\tilde{t}+a} / z_{i j \tilde{t}+a}^{*}\right), a \geq 0 .
$$

In the balanced growth path described above, $s_{i j a}$ follows a Brownian motion starting at $s_{i j 0}$ with drift $\mu$ and standard deviation $\sigma_{I}$. Note that, given the expression for sales, equation (11), the variable $s_{i j a}$, and the aggregate variables summarize current firm behavior in market $j$. In particular, if $s_{i j a}<0$, the firm does not currently sell in market $j$. Thus, firm growth and selection in a market can both be characterized as a function of $s_{i j a}$.

\subsection{Selection}

I first derive analytical expressions for firm and cohort survival rates that provide an intuitive interpretation of the workings of firm-selection in the model. The survival function for a firm of initial size $s_{i j 0}=s_{0}>0$ is defined as the probability of selling in market $j$ after $a$ years, conditional on initial size in the market, and is given by

$$
S_{i j}\left(a \mid s_{i j 0}=s_{0}\right)=\Phi\left(\frac{s_{0}+\mu a}{\sigma_{I} \sqrt{a}}\right)
$$

where $\Phi(\cdot)$ denotes the cumulative distribution function of the normal distribution. This expression implies that firms with larger initial size in a market, $s_{i j 0}=s_{0}>0$, have a higher probability of selling in this market in the next period. This survival function implies that the probability of exit of a firm in a market depends on its relative size in that market, $s_{0}$.

Integrating the firm survival rates across different initial sizes, the model delivers an analytical characterization of the survival rate of a given "incumbent" cohort of firms from $i$ that sell to $j$,

$$
\left.S_{i j}(a)=\left[\Phi\left(\frac{\mu}{\sigma_{I}} \sqrt{a}\right)+e^{a\left(\frac{\theta_{2}^{2} \sigma_{I}^{2}}{2}+\theta_{2} \mu\right.}\right) \Phi\left(-\frac{\theta_{2} \sigma_{I}^{2}+\mu}{\sigma_{I}} \sqrt{a}\right)\right] .
$$

This cohort survival rate depends on the productivity distribution parameter $\theta_{2}$ that reg- 
ulates the relative density of firms around the exit productivity cutoff, $z_{i j t}^{*}$, and, thus, the number of firms that are likely to exit in the near future. Note that if $\mu<0$ both the firm and the cohort survival rates decrease monotonically with $a$.

Overall, the model is qualitatively consistent with evidence on firm exit. In particular, it is consistent with the high attrition of new entrants, since all the entry happens from the cutoff $z_{i j t}^{*}$. In fact, if the resulting distribution of productivities has a large density around $z_{i j t}^{*}$ there is high exit for incumbent firms as well. These results are driven by the productivity process adapted by Luttmer (2007) and the entry-exit process postulated in this paper, which drops sunk costs of entry. The resulting large attrition rates of entrants are consistent with the US census data of Dunne, Roberts and Samuelson (1988) challenging the view that sunk costs are necessary to explain the entry and exit behavior of firms. In addition, by creating a band of inactivity for entrants, sunk costs imply that the size of entrants is larger than the size of exiters. Instead, the model here implies that the average size of entrants is, by construction, equal to the size of exiters, an implication consistent with the US data and the Brazilian exporting data. ${ }^{21}$

Recall that the parameters $\beta$ and $\sigma$ do not play a role in entry and exit since they do not affect the evolution and the steady-state distribution of firm productivities in the balanced growth path. These two parameters are crucial for firm growth, however, which I discuss next. In particular, I compare the predictions of the endogenous cost model (Arkolakis (2010)) when $\beta>0$ and the fixed cost model (Chaney (2008)) when $\beta \rightarrow 0$.

\subsection{Growth}

To set ideas, I start by summarizing the findings of a large literature devoted to analyzing the relationship between firm growth and firm size using micro data. Research as early as Mansfield (1962) has demonstrated a robust inverse relationship between expected firm growth and initial firm size for surviving firms. An inverse relationship between the variance of growth rates and initial firm size also has been established as discussed in Sutton (1997) and Caves (1998). These stylized facts can be summarized as follows:

Fact 1 (F1). For surviving firms the growth rate and its variance decline with initial firm size.

\footnotetext{
${ }^{21}$ I discuss these facts in Appendix B as well as different calibrations of the Luttmer (2007) model with a sunk-cost. These calibrations suggest that the sunk-cost model requires the average size of entrants to be about 15\%-25\% larger than the average size of exiters and that hazard rates for entry cohorts are initially increasing, as argued by Ruhl and Willis (2008). Both implications contradict the data presented in Dunne, Roberts and Samuelson (1988) and in Ericson and Pakes (1998). Nevertheless, the assumption of sunk costs can generate the observed hysteresis to firm decisions in response to exchange rates shocks, as in Baldwin and Krugman (1989).
} 
Similar findings have been reported for exporter growth (see for example Eaton et al. (2008) and the discussion in the next section) so that F1 holds for exporter growth as well. In fact, in the model with a geometric Brownian motion, given the CES preferences specification, two distinct forces act so that Gibrat's law does not hold for the growth of sales of firms in each market: selection effects and the market penetration technology. These two forces affect the growth of a firm in each market in the same way. I analyze each of these forces separately by looking at the growth of sales of a firm in a market over the period of $a$ years, $\hat{G}_{i j a}=\log r_{i j \tilde{t}+a}\left(s_{i j a}\right)-\log r_{i j \tilde{t}}\left(s_{i j 0}\right)$.

\subsubsection{Firm Selection and Firm Growth}

I first examine the changes in the mean and the variance of the natural logarithm of sales for the case of $\beta \rightarrow 0$. The moments of the logarithm of sales function can be obtained using the moment generating function. The expected growth given initial size is ${ }^{22}$

$$
E\left(\hat{G}_{i j a} \mid s_{i j a}>0, s_{i j 0}=s_{0}\right)=\left(\alpha g_{\eta}+g_{\kappa}\right) a+(\sigma-1) \mu a+(\sigma-1) \sigma_{I} \sqrt{a} m\left(-\frac{s_{0}+\mu a}{\sigma_{I} \sqrt{a}}\right)
$$

where $m(x)=\varphi(x) / \Phi(-x)$ is the inverse Mills ratio and $\varphi(x)$ is the pdf of the standard normal distribution. The third term of this expression appears because of selection and is decreasing in size, $s_{0}$, and converges to 0 for large $s_{0}$. Thus, the force of selection by itself implies that growth rates are declining in initial size. Gibrat's law for firm sales is approximately true for the largest firms, which are unaffected by the selection forces.

The variance of firm growth given initial size is

$\mathcal{V}\left(\hat{G}_{i j a} \mid s_{i j a}>0, s_{i j 0}=s_{0}\right)=(\sigma-1)^{2} \sigma_{I}^{2} a\left\{1-m\left(-\frac{s_{0}+\mu a}{\sigma_{I} \sqrt{a}}\right)\left[m\left(-\frac{s_{0}+\mu a}{\sigma_{I} \sqrt{a}}\right)+\frac{s_{0}+\mu a}{\sigma_{I} \sqrt{a}}\right]\right\}$.

The term in brackets incorporates the effects of selection, and is increasing in its argument, $\frac{s_{0}+\mu a}{\sigma_{I} \sqrt{a}} \cdot{ }^{23}$ In turn, $\mathcal{V}$ is increasing in $s_{0}$ and, in fact, for large $s_{0}$ it converges to $(\sigma-1)^{2} \sigma_{I}^{2} a$. Given that the normal distribution of growth rates is unimodal, censoring of the negative growth rates of some small firms reduces the variance of small firm growth rates.

To recapitulate, the selection mechanism alone implies that surviving small firms grow faster than large firms but it also implies that the variance of firm growth increases with

\footnotetext{
${ }^{22}$ The correction for the selection bias is different from the specification of Heckman (1979) in that the entry and sales decisions are perfectly correlated in my case (both driven by productivity shocks). A partial correlation can be generated, for example, if there exists randomness in a term that would influence entry but is not perfectly correlated to sales. The obvious candidate term in this model is the parameter $1 / \psi$.

${ }^{23}$ The proof can be found in Sampford (1953). More generally, the result that the left truncated variance is decreasing in the truncation point (and thus is increasing in the size of the firm) holds for all distributions with logconcave pdf (see An (1998)) such as the normal distribution.
} 
firm size, an implication in sharp contrast to F1. ${ }^{24}$ Below, I show how the endogenous cost model reconciles these two relationships.

\subsubsection{Market Penetration Technology and Firm Growth}

To characterize the effects of the market penetration technology on the growth of firms, independent of the selection effect, I focus on the instantaneous growth rate of a firm in each market, which is not affected by entry and exit. This analysis can be performed by applying Ito's lemma to expression (11) for firms with initial size in the market of $s_{i j 0}=s_{0}>0,{ }^{25}$

$$
\frac{d r_{i j}\left(s_{0}\right)}{r_{i j}\left(s_{0}\right)}=\left[\alpha g_{\eta}+g_{\kappa}+\mu \frac{h^{\prime}\left(s_{0}\right)}{h\left(s_{0}\right)}+\frac{1}{2} \sigma_{I}^{2} \frac{h^{\prime \prime}\left(s_{0}\right)}{h\left(s_{0}\right)}\right] d a+\left[\sigma_{I} \frac{h^{\prime}\left(s_{0}\right)}{h\left(s_{0}\right)}\right] d W
$$

where $h\left(s_{0}\right) \equiv e^{\bar{c}_{1} s_{0}}-e^{\bar{c}_{2} s_{0}}$.

In equation (30), the first and second bracketed terms represent the (instantaneous) growth, $E(d r / r)$, and the standard deviation of growth of a firm of size $s_{0}$ respectively. Proposition 4 characterizes the relationship between the instantaneous growth rates of firms of size $s_{i j 0}=s_{0}$ in a given market for different values of $\beta$.

Proposition 4. Suppose that A2-A3 and R1 hold. Then:

a) If $\beta \rightarrow 0$ the instantaneous expected growth rate of all firms is the same.

b) There exist a $\beta^{\prime} \in(0,+\infty)$ such that $\partial(E(d r / r)) / \partial s_{0}<0 \forall \beta>\beta^{\prime}$, and $\partial(E(d r / r)) / \partial s_{0}>$ $0 \forall \beta<\beta^{\prime}$, for all firms with $s_{0}>0$.

Proof. To prove part (a) of the proposition, I use the l' Hospital rule to compute the terms in expression (30) for $s_{i j 0}=s_{0}$,

$$
h^{\prime}\left(s_{0}\right) / h\left(s_{0}\right) \stackrel{\beta \rightarrow 0}{\longrightarrow}(\sigma-1), \frac{h^{\prime \prime}\left(s_{0}\right)}{h\left(s_{0}\right)} \stackrel{\beta \rightarrow 0}{\longrightarrow}(\sigma-1)^{2} .
$$

For part (b), I look at the derivative of the first parenthetical term in expression (30) with respect to $s_{0}$. In Appendix B.5, I show that the sign of this derivative is negative if and only if

$$
\beta>(\sigma-1) \sigma_{I}^{2} 2^{-1}\left[\mu+(\sigma-1) \sigma_{I}^{2}\right]^{-1}>0 .
$$

\footnotetext{
${ }^{24}$ In the Klette and Kortum (2004) model, the variance unconditional on survival is inversely proportional to firm size. This is so because the sales of the firm are proportional to the number of goods that the firm has and each good has the same variance. Due to this specification the model does not predict a Pareto distribution of firm sizes in the right tail.

${ }^{25}$ See Dixit and Pindyck (1994), Chapter 3, for the details of Ito's lemma and related derivations. Because Brownian motion paths exhibit infinite variation for any given time interval, standard calculus does not apply. The application of Ito's lemma requires the sales function to have a continuous second derivative. The function $h(s)$ does so for $s>0$, but it does not attain continuous derivatives at $s=0$.
} 
If $\mathrm{R} 1$ is not satisfied, there does not exist a value of $\beta$ for which the growth rates are decreasing in size. The growth rate for very large firms, $s_{0} \rightarrow \infty$, is the same as the growth rate of all firms for $\beta \rightarrow 0$.

For $\beta>0$, the model with endogenous market penetration costs also predicts an inverse relationship between the sales of firms in a market and the instantaneous variance of their growth rates for that market as illustrated in the following proposition:

Proposition 5. Suppose that A2-A3 hold. Then:

a) If $\beta \rightarrow 0$, the instantaneous variance of the growth rate is independent of initial firm size.

b) If $\beta>0$, the instantaneous variance of the growth rate decreases in initial firm size.

Proof. See Appendix B.

Overall, the endogenous cost model, with a high enough $\beta$, reconciles the inverse mean growth-size relationship with the inverse variance of growth-size relationship, as indicated in F1. The intuition for both results is as follows. For a given percentage change in firm productivity, percentage changes in the intensive margin (sales per consumer) are the same across firms but percentage changes in the extensive margin of consumers are large for firms with few consumers. Thus, for a firm whose size is relatively small the effective demand elasticity is very large, and so is its expected growth rate and growth volatility, as well. A large firm makes only relatively small adjustments to its extensive margin, and its demand elasticity approaches a constant, as discussed in the proof of Proposition 4.

\section{Calibration}

The goal of this section is to calibrate the model without using data on individual firm growth, as a means to evaluate the ability of the model to predict the relationship between firm growth and size. For the calibration, I assume that the model is in a balanced growth path. Table I lists the values of the parameters used for the benchmark calibration of the endogenous cost model as well as the sources which they are based on.

\subsection{Parameters from the Static Model}

To calibrate the parameters $\alpha, \beta$, and the ratio $\tilde{\theta}=\theta_{2} /(\sigma-1)$, I follow the calibration of Arkolakis (2010) that uses a cross-section of French exporters, as each cross-section of the dynamic model is identical to the static setup in that paper. The choice of $\tilde{\theta}$ can be thought 
Table I: Benchmark calibration of the endogenous cost model

\begin{tabular}{llc}
\hline Benchmark param. & Value & Source/Target \\
\hline Cross section & & Cross-sectional exporting data \\
$\alpha$ & 0.44 & Arkolakis (2010) \\
$\theta_{2}$ & 8.28 & Eaton \& Kortum (2002) \\
$\beta$ & 0.915 & Arkolakis (2010), Eaton, Kortum \& Kramarz (2011): \\
$\tilde{\theta}(\sigma)$ & $1.65(6.02)$ & Sales advantage of prolific exporters in France \\
Balanced growth & & US macroeconomic aggregates \\
$g_{\eta}$ & 0.0122 & US population growth \\
$g_{k}$ & 0.02 & US GDP growth \\
$g_{E}+g_{A}$ & 0.0179 & US GDP growth \\
Idiosyncratic productivity & & US manufacturing census data \\
$\mu\left(g_{I}\right)$ & $-0.0184(-0.0005)$ & Exit rates of 1963 cohort from Dunne, Roberts \\
$\sigma_{I}$ & 0.0682 & \& Samuelson (1988) (\& the value of $\left.\theta_{2}\right)$
\end{tabular}

of as picking the value of $\sigma$ for any given value of $\theta_{2}$. The parameter $\alpha$ governs firm entry as a function of the population of the market and I set $\alpha=0.44$ to match the entry of French exporting firms into markets with different population sizes.

The parameters $\beta$ and $\tilde{\theta}$ jointly determine the cross-sectional sales heterogeneity of firms. They can be considered independently of the other parameters of the model since, given $\theta_{2}$, their choice does not affect firm selection. With the benchmark choice of $\beta=.915$ and $\tilde{\theta}=1.645$, the model matches the size advantage of French exporters in the domestic market compared with firms that export to only a few markets or not at all. In the fixed cost model, given $\beta=0$, I set $\tilde{\theta}=1.49$, following Arkolakis (2010), this being the parameter choice that best matches the size advantage of French exporters.

A "unified" theory that aspires to explain firm selection and growth should generate the cross-sectional firm size distribution observed in the data. Figure II plots the sales of the firms (divided by mean sales) in logarithms for different firm sales percentiles, using information from the US Small Business Administration. It clearly illustrates that a large proportion of the firms in the data are very small. In fact, as has been shown by Axtell (2001), the size distribution of the larger firms can be approximated by the Pareto distribution. These features are similar to those of the distribution of sales of French firms to individual destinations studied by Eaton, Kortum and Kramarz (2011). Thus, the nature of the French data, used for the calibration of this model, appears to be similar to that of the US data used to verify different predictions of the model.

The predictions of the benchmark model for the overall firm size distribution are also illustrated in Figure II. Under both parameter configurations, the model can match the Pareto right tail of the distribution, but only the model with $\beta>0$ can explain the existence 
Figure II: Distribution of total firm sales: Data and model

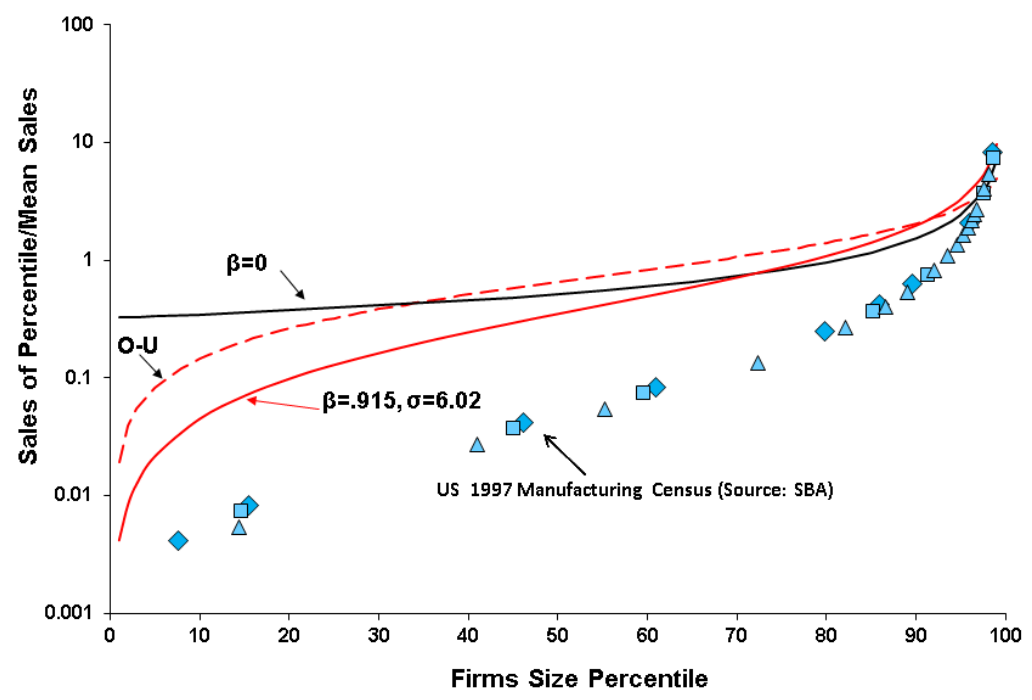

Note: Data from the Small Business Administration (SBA) 1997, 2002, and 2007 censuses. The maximum point of each bin reported in the data and the corresponding number of firms are used to plot the sales size of the firms and the corresponding percentiles.

of many small firms in the data, a deviation from Pareto. If $\beta>0$, small firms endogenously reach very few consumers which leads to a size distribution more curved than the Pareto.

Given the calibrated value of $\tilde{\theta}=\theta_{2} /(\sigma-1)$, I exploit the static predictions of the model to calibrate the value of $\theta_{2}$, and thus $\sigma$. The parameter $\theta_{2}$ is key in determining the aggregate elasticity of bilateral trade flows and the welfare properties of a wide class of trade models as argued by Arkolakis, Costinot and Rodríguez-Clare (2012). Thus, I use the estimate for the trade elasticity of Eaton and Kortum (2002), $\theta_{2}=8.28$, which falls in the middle of the range of estimates reviewed by Anderson and Van Wincoop (2004). This parameter is kept fixed when I look at the predictions of the fixed cost model. Given $\theta_{2}=8.28$, the value of $\sigma$ which is consistent with $\tilde{\theta}=1.645$ is $\sigma=6.02$, which is in the ballpark of the estimates of Broda and Weinstein (2006). This value also implies a markup of around 20\% which is consistent with the values reported in the literature (see, for example, Martins, Scarpetta and Pilat (1996)). Given $\theta_{2}=8.28$, the fixed cost model requires $\sigma=6.55$.

\subsection{Parameters Governing Dynamics}

The remaining parameters are chosen so that the balanced growth path and productivity dynamics are the same across the different versions of the model. To determine the value of the parameters $g_{\eta}, g_{\kappa}$, and $g_{E}+g_{A}$, which govern the aggregate dynamics of the model, I use macroeconomic data for the US economy. Since the growth of the population in the US 
from 1960 onwards is around $1.22 \%$ and the growth rate of real GDP per capita is around $2 \%$, I set $g_{\eta}=0.0122$ and $g_{\kappa}=0.02$. Given the definition of $g_{\kappa}$, the sum of the growth of the quality of new ideas and the growth rate of aggregate technology in the benchmark calibration is ${ }^{26}$

$$
g_{E}+g_{A}=g_{\kappa}-g_{\eta}(1-\alpha) /(\sigma-1)=0.0179 .
$$

For the calibration of parameters $\mu$ and $\sigma_{I}$ that govern productivity (and thus firm) dynamics, note that $\theta_{2}$, which is an explicit function of these two parameters (equation 18), has been set to 8.28. Thus, an additional relationship from the model that relates these two parameters must be used. I employ equation (29) for incumbent cohort survival rates and obtain the same information from the data by looking at the incumbent cohort exit rates of US manufacturing firms as reported by Dunne, Roberts and Samuelson (1988). Using these two relationships, together with the empirical values of the elasticity of trade and the exit rates for the first cohort analyzed by Dunne, Roberts and Samuelson (1988)-42\% in 4 years-, a simple method of moments implies $\mu=-1.84 \%$ and $\sigma_{I}=6.68 \%$, and, in turn, $g_{I}=\mu+g_{E}=-0.0005 \%$, for the benchmark calibration. The negative value of the growth of the productivity of the incumbent ideas is an artifact of the model's assumption that all exit happens from the cutoff point. ${ }^{27}$

To summarize, the crucial parameters in this calibration are $\beta, \sigma, \mu, \sigma_{I}$, and also $\theta_{2}$ (the parameters $g_{\eta}, g_{\kappa}, g_{E}+g_{A}$, serve to construct a balanced growth path and $\alpha$ plays a minor role in the results). Given that $\theta_{2}$ is a function of $\mu$ and $\sigma_{I}$, the dynamic model has only one net parameter more than its static counterpart.

For the calibration of the O-U process, note that it was specified as an explicit generalization of a Brownian motion, with one additional parameter $\rho$. In models where, by assumption, firm productivities follow an $\operatorname{AR}(1)$ process, the estimates of the autoregressive coefficient of the productivity process that are consistent with the data are close to one (see for example Hopenhayn and Rogerson (1993), Lee and Mukoyama (2008), and Alessandria and Choi (2007)). To be in line with these estimates, I choose $e^{-\rho}=0.95$. I retain the calibration of $\mu$ and, given the value for $\rho$, I recalibrate the parameter $\sigma_{I}$ so that the O-U model generates the four year exit rates in the census data, exactly as in the case of a geometric Brownian motion. Because the resulting distribution is not invariant to truncation, as in

\footnotetext{
${ }^{26}$ Given that $\mu=g_{I}-g_{E}$, there is an additional degree of freedom in the calibration. I use this extra degree and choose $g_{E}$ so that $g_{\kappa}$ is the same in all the specifications of the model even if $\sigma$ 's might differ (equation 26).

${ }^{27}$ Consider, for example, the very simple extension of the model with an exogenous death rate, $\delta$. Given that the probability of endogenous exit for firms with large sizes is (practically) zero, I can calibrate $\delta$ by looking at the death rate of these firms. This information was obtained by the US Manufacturing Census during the period 1996-2004, where the tabulation of the largest manufacturing firms includes those with 500 or more employees. That calibration would yield $\mu=-1.64 \%$ and $g_{I}=0.0024$.
} 
the Pareto case, the choice for the number of ideas, $J_{i}$, also matters so that multiple $\sigma_{I}$ can generate the same exit rate. I choose $\sigma_{I}=0.08$, which, given the calibration of aggregate parameters in the next subsection, provides a satisfactory fit for the size distribution of sales (Figure II) and the relationship between firm growth and initial size discussed below. The requirement of Proposition 2 is satisfied as long as $\rho>0$ and $\mu(\sigma-1)-g_{B}<0$, as I show in the online appendix.

\section{Discussion of parameter choices: Firm exit, growth, and some basic statistics} Given the calibrated parameters I turn to assess the predictions of the model for firm exit and growth in comparison to the empirical evidence. Since the predictions of the model are the same for the growth rate of sales in both the domestic or exporting markets I use evidence on firm domestic and exporting activity. ${ }^{28}$

In Table II, I present the predictions of the calibrated model for the cumulative exit rates of "incumbent" and "new cohorts" and compare them with the Dunne, Roberts and Samuelson (1988) data. The term "incumbent cohort" refers to the firms that were in the market at a certain census year (normalized as year 0). The survivors of that cohort at year $t$ are the firms from the cohort that sell in the market at year $t$ and in all previous census years of the cohort. "Entry cohort" refers to firms that enter the market between the current census and the previous one. Thus, by construction, an incumbent cohort includes the surviving firms from all past entry cohorts as well as the firms in the current entry cohort. In the US data, in a time frame of 15 years, only about a quarter of the incumbent cohort firms and about $12 \%$ of the entry cohort firms are still active. The exit rates of the entry cohorts are also consistently higher than those of the incumbent cohort. Given that the incumbent cohorts also include firms from the current entry cohorts, exit rates of the entry cohorts account for a large part of the overall incumbent-cohort exit.

To generate comparable statistics, I conduct a five-year census in the model-generated data. $^{29}$ The benchmark model is calibrated to match the four-year exit rate of the first census, but it nonetheless closely matches the exit rate of incumbent cohorts for a time frame of two decades as well as the entry cohort exit rates for 15 years. The high exit

\footnotetext{
${ }^{28}$ In the online data appendix, I test the model prediction that the growth of the firm in each market depends on its size in the market and not on its overall size (captured by a firm fixed effect), and find strong support for this prediction. Assuming that the productivity (or, equivalently, some random demand shock) in each destination is the weighted sum of independent Brownian motions allows to model sales of each firm in different destinations are imperfectly correlated, without affecting any of the rest of the results of the model. The specification of the weights can determine the correlation across destinations and thus gives a dynamic interpretation for the market-specific demand shocks modeled by Eaton, Kortum and Kramarz (2011) (see also Demidova, Kee and Krishna (2006) and Pozzi and Schivardi (2012)).

${ }^{29}$ I follow the methodology of Dunne, Roberts and Samuelson (1988) as closely as possible and classify a firm that exits in a census-year and re-enters in a later census as an exiter when it leaves and as an entrant when it re-enters (see footnote 13 in their paper).
} 
Table II: Cohort exit rates: Data and model

\begin{tabular}{lccc}
\hline Statistic / Cohort year & 5 & 10 & 15 \\
\hline Entry cohort exit rate & & & \\
Data (mean '67-'77 cohorts) & 0.62 & 0.79 & 0.88 \\
Model & 0.66 & 0.76 & 0.85 \\
Inc. cohort exit rate & & & \\
Data (mean '67-'77 cohorts) & 0.48 & 0.65 & 0.76 \\
Model & 0.46 & 0.66 & 0.77
\end{tabular}

Source: Dunne at al. 1988 and model simulations. All the data are based on firm activity in 4-digit manufacturing SIC industries and the numbers are reported as means across industries.

rates for the first cohort years are due to the high concentration of firms close to the cutoff productivity level. This concentration is even higher among entrants and accounts for the differences in exit rates between entry and incumbent cohorts. The O-U model is calibrated to match the four-year exit rate in the data and implies results very close to those in the benchmark model.

To check the predictions of the model in regard to the entry-exit process, I also use exporting transactions data for Brazil. These data allow me to monitor exporters that continuously enter and exit a specific market, even if their sales in this market are very small. ${ }^{30}$ The probability that a Brazilian firm that exits a market will export again in the same market in the next three years, computed as the mean across the top 50 destinations of Brazilian exporters in the years 1990-2001, is around 28\%. The calibrated model predicts that this percentage is slightly higher, around $33 \%$. The number is lower in magnitude but still substantial for domestic producers in the case of Belgium, about $12 \% .{ }^{31}$ Consistent with the theory, the empirical findings imply that re-entry is a prevalent phenomenon both for domestic and exporting sales.

Finally, note that increasing $\beta$ above the benchmark calibration value of 0.915 has small effects on the size distribution but with $\tilde{\theta}$ set to the preferred value of Luttmer (2007), 1.06, the model closely fits the firm size distribution of the smaller firms. However, with this parameter combination the model substantially overpredicts the market shares of incumbent cohorts in comparison to the data (by about 15 percentage points in about 15 years). The market shares of incumbent cohorts predicted by the benchmark model are very close to

\footnotetext{
${ }^{30}$ In the online data appendix, I argue that qualitatively the profile of exit and growth of the Brazilian exporters is very similar to the one in the US manufacturing data. The main difference that stands out in the export data is the higher exit rate of exporters in their early years. For example, the exit rate of entry cohorts is approximately 15 percentage points higher in the export data for both incumbent and entry cohorts.

${ }^{31}$ I thank Emmanuel Dhyne for computing this number using the Belgian data. The data refer to Belgian firms domestic sales from 1996 to 2012.
} 
census cohort market shares reported by Dunne, Roberts and Samuelson (1988) as discussed in Appendix A.

\subsection{Aggregate Parameters}

To study cross-firm reallocations of exporters and non-exporters in Section 5.2 the model requires additional calibration. In particular, I need to specify a multi-country version of the model where I specify and all the relevant parameters: the bilateral trade costs, aggregate technology shocks, and population for each country. The analysis requires a large time panel of positive bilateral trade flows in order to construct the ages of firms and exporters. Thus, I restrict my analysis to 22 countries that allows me to use the maximum time extent of the data, the years 1980-2006. ${ }^{32}$ The maximum age of a firm or exporter that can be observed in this panel is 25 years. A new firm is assigned an age 0 and an exit is an idea that records positive sales in one year and zero sales the next one.

Trade data are obtained from the Centre d'Etudes Prospectives et Informations Internationales (CEPII) web-site and gross domestic product data from the World Development Indicators database. Using this information, I construct the $N \times N$ matrix of trade shares and the $N \times 1$ vector of aggregate expenditures. In order to separate out aggregate technology from trade costs, I impose symmetry on trade costs. This effectively reduces the dimensionality of the parameter space in the model, and resolves the under-identification problem that is inherit in gravity trade models (see Burstein and Vogel (2012) and Allen, Arkolakis and Takahashi (2014)).

For all the versions of the model, the targeted moments are the bilateral market shares for each year, the ratio of the GDP of each country relative to the US in the initial year of the calibration, and the growth of real income afterward. I choose $A_{i t}$ and $\tau_{i j t}$ for each year to minimize the sum of the squared distance between these moments and corresponding model predictions. In practice, the model precisely fits the levels of income for each year and closely matches the relative trade shares, with the average absolute error across bilateral shares being less than 0.0063 for any year. In addition, the estimated trade costs are correlated with geographic variables as expected: a regression of the logarithm of estimated trade costs on origin and destination fixed effects, distance, border and language dummies (using data from CEPII) implies that trade costs decrease with distance and are lower for country pairs that share a border or a language.

\footnotetext{
${ }^{32}$ These countries are Australia, Austria, Brazil, Canada, China, Denmark, Finland, France, Germany, Greece, Italy, Japan, Mexico, Netherlands, Norway, Portugal, Russia, Spain, Sweden, United Kingdom, and the United States. There are only 3 instances of zero bilateral trade flows in the entire sample which I impute with very low positive trade shares.
} 


\section{$5 \quad$ Implications for Exporter Growth}

This section investigates the implications of the calibrated model for exporter and firm growth. First, I analyze the sources of exporter growth that arise in the model by looking at the density of exporter growth rates as a function of firm size and age. Second, I examine the implications of cross-firm reallocations on growth and firm measured productivity by looking at the economy in a balanced growth path and after exogenous changes in trade costs and aggregate technology.

\subsection{Sources of Exporter growth}

I turn next to study the implications of the model for the distribution of exporter growth rates in each market as a function of exporter size and age. To do so, I illustrate a number of stylized facts in the Brazilian data that relate to these implications. As I show in the online data appendix these facts are similar across the top exporting destinations of Brazilian exporters, which supports the prediction of the model that the distribution of growth rates, as a function of size and age, is common across destinations.

Growth and Exporter Size To check the predictions of the model for firm growth, I use data on the sales of Brazilian exporters in the US, since the US is the biggest export market for Brazilian firms. Figure III depicts the mean growth of surviving firm sales as a function of the initial sales percentile. To stress the similarities of exporter growth with overall firm growth I also use the data of Davis et al. (2009) for all US firms. The pattern of this growth is similar in both datasets: the smallest firms and exporters have particularly high growth rates while the largest ones have almost zero growth on average. In fact, in both datasets, mean growth rates typically decline monotonically with initial size.

Figure IV adds model predictions to the picture. The fixed cost model clearly falls short of quantitatively explaining the relationship between growth and initial size in the data. The force of selection generates an inverse growth-size relationship, but this force, by itself, is insufficient to generate the large growth rates of small firms or exporters. The endogenous cost model generates a strong inverse relationship, implying that firm choices at the extensive margin are key in this analysis. Notice that these changes are prominent only among small sizes, and induce the endogenous cost model to over-predict the growth rates for small firms and under-predict those of large firms. ${ }^{33}$ The inverse size-growth relationship is partially

\footnotetext{
${ }^{33}$ In the calibrated model, the expected growth rates of the largest firms tend to zero, in line with the numbers reported by Davis et al. (2009) and the Brazilian exporting data. However, for the benchmark parameter choices of the endogenous cost model and the fixed cost model, the standard deviation of sales growth for the largest firms converges to $(\sigma-1) \sigma_{I}=34 \%-38 \%$. This number is about 2 or 3 times of what is reported by Davis et al. (2007) and Comin and Mulani (2007) and higher than what is implied by the
} 
Figure III: Survivor growth rates and sales percentiles: US firms and Brazilian exporters in the US

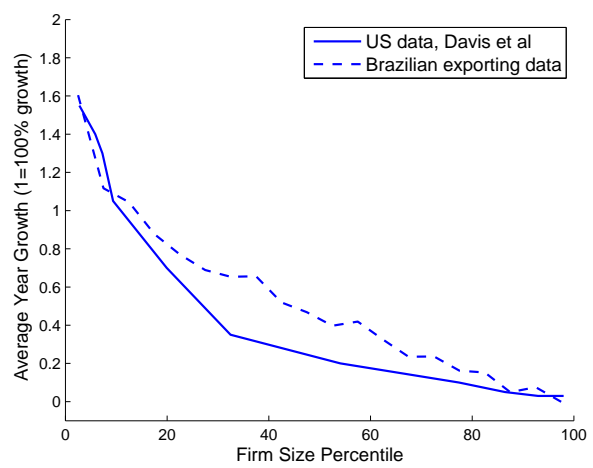

Note: US data: The growth rate in the US data is measured as total sales of US firms in 2000 divided by the mean of their total sales in 2000 and 1999. This measure can be considered as a lower bound to the measure of growth computed using the standard growth metric (ratio of sales in 2000 to sales in 1999 minus 1), given its tendency to lower the estimates of growth rates. Brazilian data: Firms are sorted in each year according to their initial size. Then, I compute their size percentile in each year and their one-year growth rates. I divide firms into 20 groups, each with an equal number of firms, based on their computed percentile and I compute the mean one-year growth rate for each group. The outlier observations of growth rates of more than $900 \%$ or less than $-90 \%$ are excluded.

retained under the $\mathrm{O}-\mathrm{U}$ calibration. For most of the size range the relationship is the same but the model implies distinctly lower growth rates for the largest sizes as a result of strong mean reversion.

To explain how firm selection and firm choices at the extensive margin of consumers shape exporter growth in practice, I discuss the predictions of the model for the entire distribution of growth rates conditional on initial size in a market. To this end, I use the Brazilian exporting data and present in Figure $\mathrm{V}$ the density of growth rates for Brazilian exporters for different initial size quartiles. Firms in quartile 1 are the $25 \%$ of firms with the lowest initial sales, whereas firms in quartile 4 are the $25 \%$ of firms with the highest initial sales. This evidence indicates a fundamental difference in the distribution of growth rates of small firms compared with that of larger firms. In particular, the distribution of growth rates of smaller firms is heavily skewed toward larger rates, even larger than 100\%, while the distribution for large firms is concentrated around zero growth, and looks similar in shape to a shifted lognormal distribution. This clear violation of Gibrat's law for firm sales is consistent with fact F1. ${ }^{34}$

estimations of other models of firm dynamics as in Hopenhayn and Rogerson (1993) and Lee and Mukoyama (2008). This shortcoming of the model is studied by Luttmer (2011).

${ }^{34}$ The possibility of measurement error cannot be excluded. However, measurement error should, in principle, be symmetric. The fact that the proportion of small firms with negative growth rates is almost the same in the two histograms lowers the probability of significant measurement error. 
Figure IV: Survivor growth rates and sales percentiles: data and model

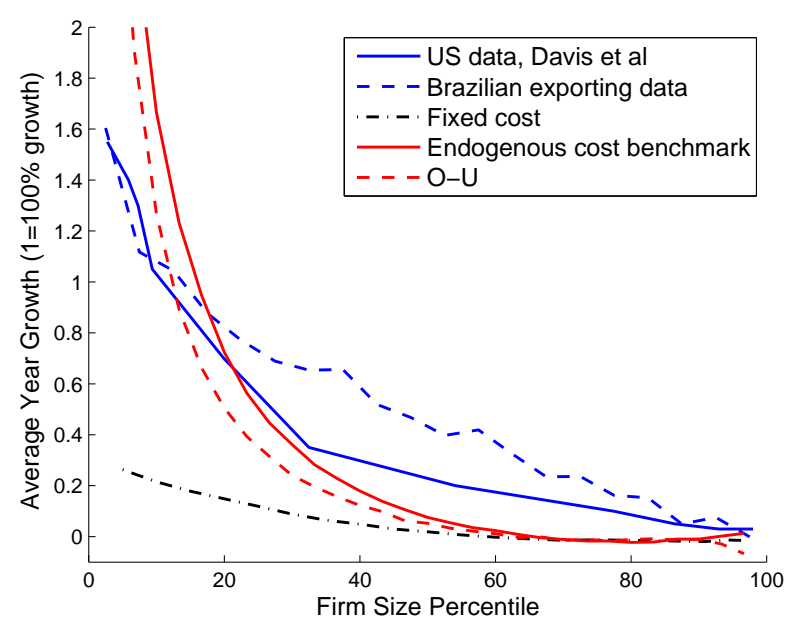

Note: Model data are generated by simulating 10,000,0000 firms. The outlier observations of growth rates of more than $900 \%$ or less than $-90 \%$ are excluded.

Figure V: Density of growth rates and size quartiles: Brazilian exporters in the US

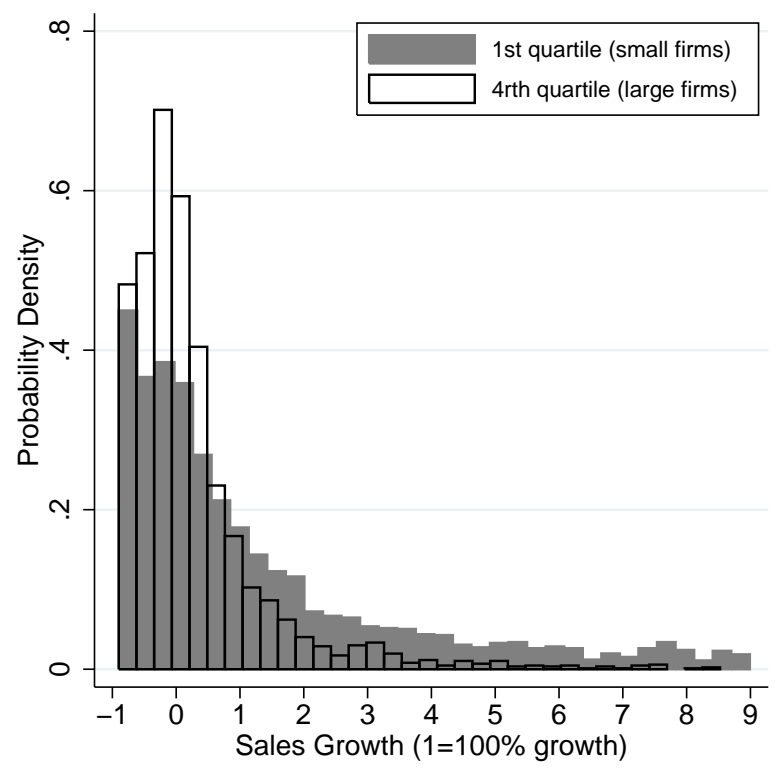

Note: The data cover the universe of Brazilian merchandise exporting transactions from 1990-2001 and are described in Molina and Muendler (2008). The outlier observations of growth rates of more than $900 \%$ or less than $-90 \%$ are excluded. Growth by decile and further details are available in Appendix A. 
Figure VI: Density of growth rates and size quartiles: Fixed cost (left panel) and endogenous cost benchmark (right panel)

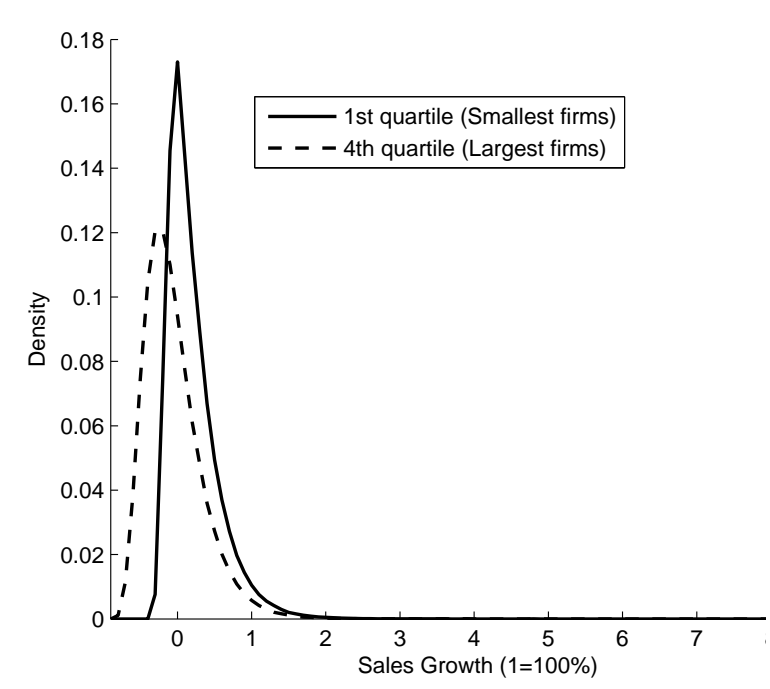

Fixed cost model

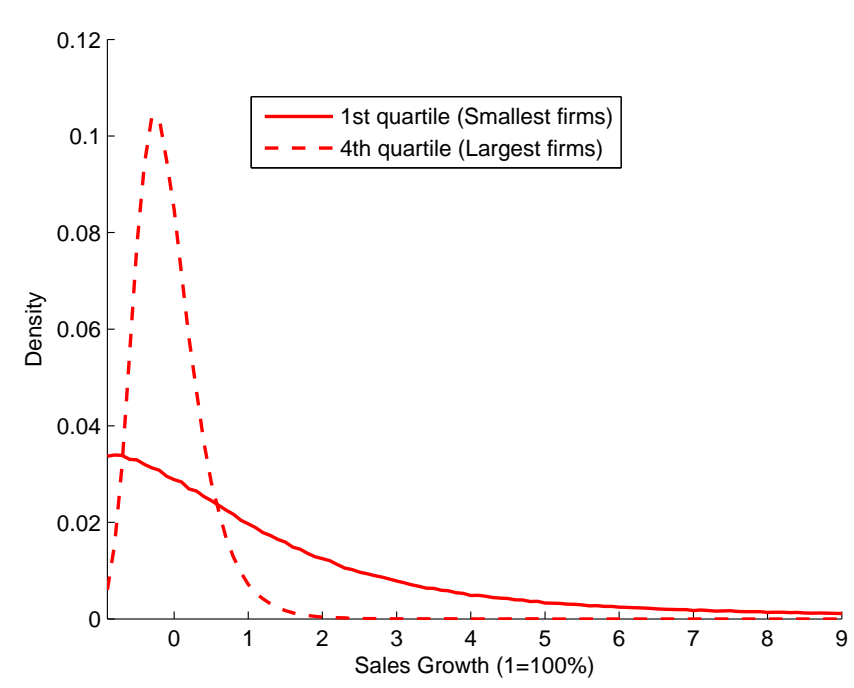

Endogenous cost model

Note: Data generated by simulating 10,000,000 firms. The outlier observations of growth rates of more than $900 \%$ or less than $-90 \%$ are excluded.

In the fixed cost model, firms with negative productivity growth are more likely to select out of the market the lower their initial size. Given that the distribution of growth rates is invariant to size in this model, the only effect of selection is a truncation of the size distribution of growth rates for small firms in quartile 1, as it can be seen in the left panel of Figure VI. Due to this truncation the expected growth rate of the surviving firms is inversely related to size. The variance of the growth rates is also larger for quartile 4 , in sharp contradiction to F1.

In the right panel of Figure VI, I plot the distribution of growth rates for the benchmark calibration of the endogenous cost model. This distribution is fundamentally different from the one implied by the fixed cost model due to the extensive margin choices of small firms. Consistent with the evidence from the Brazilian exporters, the distribution of growth rates of the smaller firms (quartile 1) is skewed toward the larger growth rates, while that of the largest firms (quartile 4) is more concentrated around zero growth and closer to a shifted lognormal. The endogenous cost model captures the higher mean and variance of the growth rate of small firms.

Growth and Exporter Age The benchmark model is not designed to generate age dependence, conditional on firm size. It nevertheless does so, as a natural consequence of firm selection and the stochastic evolution of firm productivities. On the one hand, firms 
Figure VII: Density of sizes, growth rates and exporter age: Brazilian exporters in the US
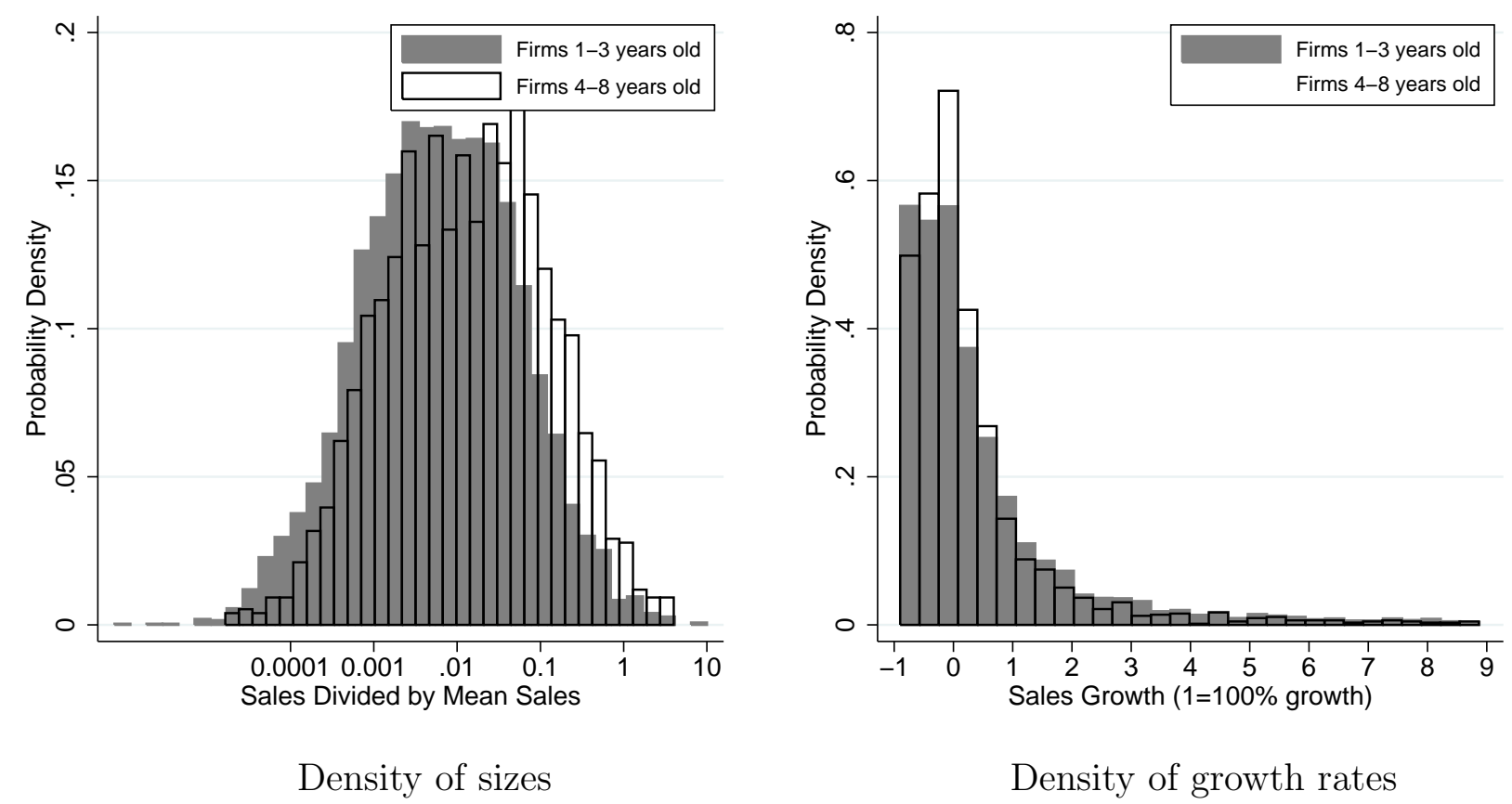

Note: The figure reports sizes and one-year growth rates of Brazilian exporters in the US. New exporters are assigned an age 0 . The outlier observations of growth rates of more than $900 \%$ or less than $-90 \%$ are excluded.

grow large only if they receive a series of positive shocks over a number of years. On the other hand, the firms that have not grown operate close to the cutoff productivity level. They are also more likely to get selected out as time goes by, if negative shocks hit them instead.

To achieve a more thorough characterization of the profile of growth of different ages, I plot the density of exporter sizes and the corresponding distribution of exporter growth rates in the two panels of Figure VII for two age groups, 1-3 years old and 4-8 years old (I omit entrants for reasons that will be apparent below). The distribution of sizes of exporters features large dispersion and the one of older exporters stochastically dominates that of younger ones: as exporters age, the distribution moves to the right. Similar facts have been reported for the overall employment distribution by Cabral and Mata (2003) and for the distribution of overall exports by Bastos and Dias (2012). Remarkably, though perhaps not unexpectedly, the distribution of growth rates is very dispersed but changes only slightly with age, with the distribution of older exporters more concentrated around zero growth.

Figure VIII illustrates the predictions of the endogenous cost model. The model generates the dispersion in the distribution of sizes and growth of exporters. Due to selection and the stochastic evolution of productivities, the size distribution shifts to the right with age. The 
Figure VIII: Density of sizes, growth rates and exporter age: Endogenous cost benchmark

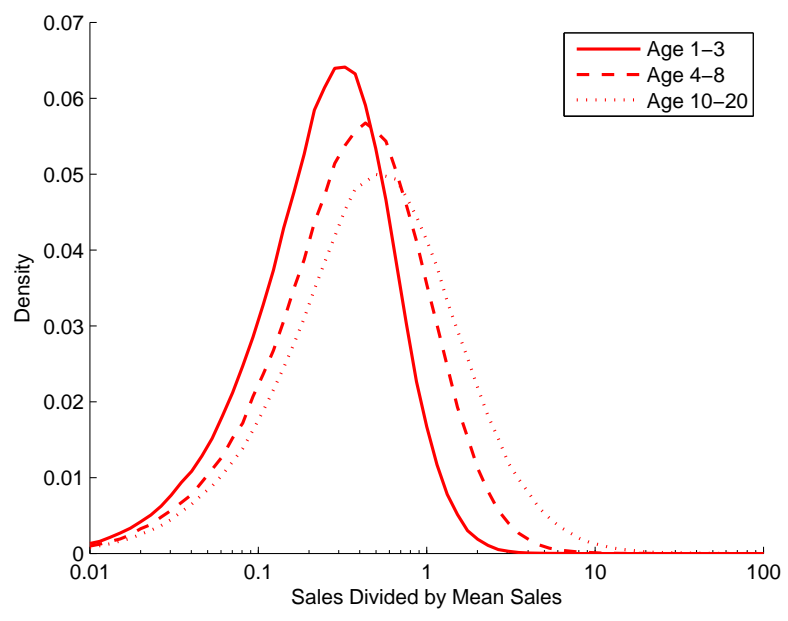

Density of Sales

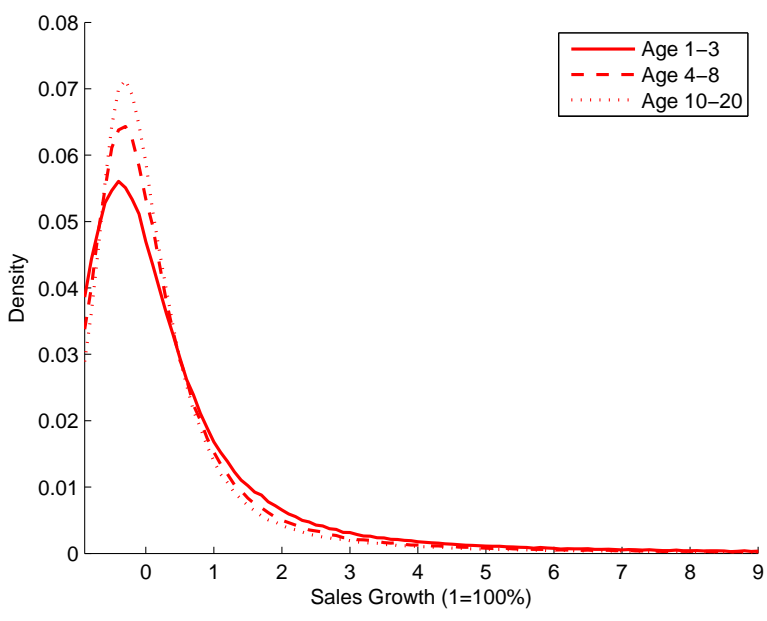

Density of Growth Rates

Model data are generated by simulating 10,000,000 firms. The outlier observations of growth rates of more than $900 \%$ or less than $-90 \%$ are excluded.

minor shift in the density of growth rates is expected: the growth distribution changes with age only because of changes in the underlying size distribution, since growth in the benchmark model is only determined by size. The fixed cost model falls short of explaining either of these relationships. First, given that entrants are concentrated around the entry point, the absence of the extensive margin of consumers implies a small dispersion in the sizes of young exporters, in contrast with the findings in the left panel of Figure VII. Second, changes at the extensive margin primarily affect the left tail of the distribution. Thus, the distribution of growth rates in the fixed cost model is much less dispersed than the data.

Growth, Size, and Age The analysis above raises the question of whether both size and age are important determinants of firm and exporter growth, since typically larger firms are also the ones that have survived for many years. There is robust evidence that firm age is an important determinant of firm growth, even after controlling for firm size (see Evans (1987a,b), Foster, Haltiwanger and Syverson (2010), Haltiwanger, Jarmin and Miranda (2011)). Existing evidence indicates that a regression of firm growth rates on firm size and age yields statistically and economically significant coefficients on both indicating that growth decreases with firm age (keeping size constant) and size (keeping age constant).

The same statistical relationship has been suggested for exporting sales (see Eaton et al. (2008) and Albornoz et al. (2009)), but recently Bernard et al. (2014) has pointed out an important aggregation bias that renders information on the growth of new exporters unreliable. In particular, if exporting sales start late in the calendar year, the recorded growth 
Table III: Growth rate on size and age groups

\begin{tabular}{lccc}
\hline & Data & Endogenous cost & $\mathrm{O}-\mathrm{U}$ \\
quartile 1 & 0.830 & 1.320 & 1.547 \\
& $(0.050)$ & & \\
quartile 2 & 0.332 & 0.164 & 0.322 \\
& $(0.046)$ & & \\
quartile 3 & 0.106 & 0.009 & 0.081 \\
& $(0.044)$ & & \\
age 1-3 & 0.093 & -0.008 & 0.026 \\
& $(0.038)$ & &
\end{tabular}

Note: In all data the outlier observations of growth rates of more than $900 \%$ or less than $-90 \%$ are excluded and entrants are dropped. Brazilian exporting data: 1990-2001 Brazilian exporters to the US. Since the maximum year age that growth can be constructed in the Brazilian data is 9 years all other exporters are ignored. Model data: generated by simulating 10,000,000 firms 10 times and taking the average. The firms are divided into size quartiles based on their current size and into age groups based on their current age and observations are treated as in the Brazilian data.

of continuing exporters may be biased upwards if these exporters are active all the months of their second year of exporting presence. In the first two columns of Table III I regress growth rates on the logarithm of exporting sales and exporter age groups, after excluding new entrants. The regression yields a statistically significant coefficient on all quartile groups and also implies a higher growth for young firms (this is statistically significant at the $5 \%$ level).

The first two columns of Table III show the same regression for the endogenous cost model and the O-U calibration (Standard errors are close to zero because of the large sample and are not reported). The endogenous cost model predicts a negative coefficient on young age. One should expect this coefficient to be close to zero because in the benchmark model there is no genuine dependence of growth on age, conditional on size. The O-U calibration generates an age effect in its favor but the coefficient is less than in the data.

\subsection{Counterfactuals: Trade and cross-firm reallocations}

I now analyze cross-firm reallocations in the simulated economy, using the benchmark model in a balanced growth path. I consider either a 10-percent worldwide decline in variable trade costs across all countries or a 20-percent positive aggregate technology shock for the United States.

Cross-firm reallocations In a period of ten years, total GDP in the US economy in the balanced growth path grows by $36.8 \%$. As shown in Table IV, in the balanced growth path the sales of firms in the first quartile grow at a very large rate while even decline for the third and fourth quartile. Because of the large adjustments in their extensive margin of 
Table IV: Growth of real sales and initial firm quartile: model simulations for the US

\begin{tabular}{cccc}
\hline \multirow{2}{*}{ Quartile $\backslash$ Scenario } & \multicolumn{3}{c}{ Growth of real sales after 10 years } \\
\cline { 2 - 4 } & Balanced growth path & Trade liberalization & US productivity growth \\
\hline 1 & $194.5 \%$ & $188.9 \%$ & $266.3 \%$ \\
2 & $27.8 \%$ & $25.1 \%$ & $57.2 \%$ \\
3 & $-2.5 \%$ & $-2.9 \%$ & $20.3 \%$ \\
4 & $-4.7 \%$ & $1.7 \%$ & $14.1 \%$ \\
Overall & $36.8 \%$ & $37.5 \%$ & $66.6 \%$
\end{tabular}

Note: Data generated by simulating 10,000,000 firms 10 times and taking averages over each group.

consumers firms of the first and the second quartile contribute positively to overall growth.

Total GDP grows slightly higher with trade liberalization by $37.5 \%$. Trade liberalization mostly benefits the largest firms which are the most prolific exporters. As a result, these firms record slightly positive growth rates in that scenario. The corresponding increase in competition reduces the domestic sales of most of the firms in quartiles 1-3 and decreases their overall growth rates. Finally, the rate of GDP growth under the aggregate technology shock scenario is $66.6 \%$. In this case all US firms grow faster. The largest firms have the benefit of increased export sales but smaller ones record large adjustments in their extensive margin of consumers and thus grow faster as well.

Trade dynamics are crucial for these results: for example, with a trade liberalization, if not for the stochastic evolution of firm productivities there would be a large reallocation of total production towards the largest firms, as in, for example, Eaton, Kortum and Kramarz (2011). Instead, with trade dynamics, there is a substantial drop in the market shares of the largest exporters. Trade still benefits these firms, but only helps them recover part of their market share lost because of dynamic reallocations.

To further analyze the forces behind firm growth, I categorize firms into size-quartiles and into different age bins: age 1-3, 4-8, and 9 or more. As it is evident from Table V, in year 1, large and old firms account for the bulk of economic activity. However, their market shares rapidly contract after 10 years by almost 20 percentage points. Interestingly the market shares of firms from the first quartile and second quartiles are basically increased or retained and there are declines for all other firms. The remainder of the increase of economic activity is accounted by new entrants.

The ability of initially small firms to retain their market share results from the large growth rates of survivors-as illustrated in Figure IV-counteracting their extremely low survivor rate of about $8.5 \%$ (only slightly higher for the older ones). The survivor rate for the largest quartile firms of age 1-4 is $52.5 \%$ and about $70 \%$ for ages 9 or more. Combined with new entry these reallocations imply that new and surviving small firms gain substantial 
Table V: Market share among survivors by initial quartile and age group: model simulations for the US

\begin{tabular}{cccccccccc}
\hline & \multicolumn{3}{c}{ Market share year 1 } & \multicolumn{5}{c}{ Market share year 11 } \\
\cline { 2 - 9 } Quartile & Age 1-3 & Age 4-8 & Age 9+ & Age 1-3 & Age 4-8 & Age 9+ & Age 1-3 & Age 4-8 & Age 9+ \\
\hline 1 & $0.4 \%$ & $0.4 \%$ & $0.7 \%$ & $0.9 \%$ & $0.8 \%$ & $1.6 \%$ & $0.8 \%$ & $0.7 \%$ & $1.5 \%$ \\
2 & $1.5 \%$ & $1.3 \%$ & $2.7 \%$ & $1.4 \%$ & $1.2 \%$ & $2.7 \%$ & $1.3 \%$ & $1.1 \%$ & $2.3 \%$ \\
3 & $2.4 \%$ & $3.0 \%$ & $7.1 \%$ & $1.7 \%$ & $2.1 \%$ & $5.1 \%$ & $1.7 \%$ & $2.0 \%$ & $4.8 \%$ \\
4 & $1.6 \%$ & $6.0 \%$ & $71.4 \%$ & $1.1 \%$ & $4.1 \%$ & $49.6 \%$ & $1.0 \%$ & $4.1 \%$ & $52.8 \%$ \\
\hline
\end{tabular}

Entrants

(1 year): $1.6 \%$

(11 years): $28.0 \%$

(11 years): $25.8 \%$

Note: The tables show the market shares of different groups in a given year. Groups defined in year 1 and "entrants" include firms that sell for the first time in the current year. Note: Data generated by simulating 10,000,000 firms 10 times and taking averages over each group.

market shares as in Kehoe and Ruhl (2013). New firms account for $28 \%$ of total sales in year 11. To better understand the rapid expansion of small firms it is worth zooming in on the behavior of surviving firms and regrouping them into size and age bins. The growth of initially small firms, conditional on surviving, is stunning: while the smallest half of these firms initially accounts for only about $13.5 \%$ of total sales they nearly double their market shares to $24.3 \%$ while at the same time the shares of the largest firms decline. In addition, the firms initially belonging to the age group of 1-3 increase their market share from about $2.5 \%$ to $5 \%$.

Trade liberalization benefits the largest and oldest firms which are the most dependent on exports. Comparing the second with the third panel in Table V, there is about a 3 percentage points increase in the survivors market shares for the US. This does not reflect any genuine size dependence relationship in the model but rather the fact that the distribution of sizes shifts to the right with age (Figure VIII), even within a given quartile, and older firms are more likely to be exporters for that reason. This expansion is mainly at the expense of firms that do not export, smaller firms and new entrants.

My findings for the rapid growth of small firms underscore their significance for economic growth. This conclusion differs from that of Davis, Haltiwanger and Schuh (1996) and Haltiwanger, Jarmin and Miranda (2011) but is nevertheless in line with their empirical findings. These authors use as a measure of firm size the average size of the initial and final year (instead of simply the initial firm size) so that firm growth appears lower for small fastgrowing firms. As reported in Appendix B.9, with this measure of firm initial size, even in my model, measured growth rates increase with size. This measurement approach introduces a systematic bias of their measurement methodology also noted by Neumark, Wall and Zhang (2011) and Huber, Oberhofer and Pfaffermayr (2013). Thus, the endogenous cost model is 
not only in line with a variety of observations in the data, but also stresses the significance of applied theoretical work in understanding the nature of firm growth.

Productivity decomposition In this dynamic setup, firm performance is determined by the evolution of firm productivities, changes in aggregate variables and firm decisions for sales, entry and exit in each market. To assess the sources of overall productivity growth in the model and the effect of trade on productivity growth, I need to consider measures of firm productivity comparable to those that researchers have considered in the data. I do so in two ways. First, I calculate measured productivity as the real value added per unit of labor production cost by using industry-level deflators, in other words "revenue productivity" (or TFPR) as considered by Foster, Haltiwanger and Syverson (2008). Following Eaton, Kortum and Kramarz (2011) revenue productivity of firm $\omega$ from country $i$ with productivity $z_{\omega}=z$ can be measured as gross production net its spending on intermediates, treating all fixed costs as purchased services, i.e.,

$$
v_{i}(z)=\frac{\sum_{j}\left[r_{i j}(z)-w_{i} F\left(n_{i j t}(z), L_{j t}\right)\right] / P_{i t}}{\sum_{j} w_{i} \tau_{i j} q_{i j t}(z) / z}=\frac{\sigma}{\sigma-1} \frac{1}{P_{i t}}\left[1-\frac{\sum_{j} w_{i} F\left(n_{i j t}(z), L_{j t}\right)}{\sum_{j} r_{i j}(z)}\right] .
$$

For more productive firms, the marketing to sales ratio is lower and thus the second term in the brackets tends to zero, i.e., revenue productivity is bounded from above. ${ }^{35}$

To aggregate across firms, overall productivity in country $i$ is

$$
\tilde{Z}_{i}=\sum_{\omega \in \Omega_{i}} s_{i}\left(z_{\omega}\right) v_{i}\left(z_{\omega}\right)
$$

where $s_{i}\left(z_{\omega}\right)$ is the share of a firm's sales in overall country sales. Following Foster, Haltiwanger and Krizan (2001), I decompose the growth of overall productivity into the contribution of continuing $(C)$, entering $(N)$, and exiting $(X)$ firms.

$$
\begin{aligned}
\tilde{Z}_{i}^{\prime}-\tilde{Z}_{i} & =\sum_{\omega \in C} s_{i}\left(z_{\omega}\right)\left[v_{i}^{\prime}\left(z_{\omega}\right)-v_{i}\left(z_{\omega}\right)\right]+\sum_{\omega \in C}\left[s_{i}^{\prime}\left(z_{\omega}\right)-s_{i}\left(z_{\omega}\right)\right]\left[v_{i}^{\prime}\left(z_{\omega}\right)-v_{i}\left(z_{\omega}\right)\right]+ \\
& \sum_{\omega \in C}\left[s_{i}^{\prime}\left(z_{\omega}\right)-s_{i}\left(z_{\omega}\right)\right]\left[v_{i}\left(z_{\omega}\right)-\tilde{Z}_{i}\right]+\sum_{\omega \in N} s_{i}^{\prime}\left(z_{\omega}\right)\left[v_{i}^{\prime}\left(z_{\omega}\right)-\tilde{Z}_{i}\right]+\sum_{\omega \in X} s_{i}\left(z_{\omega}\right)\left[\tilde{Z}_{i}-v_{i}\left(z_{\omega}\right)\right] .
\end{aligned}
$$

\footnotetext{
${ }^{35}$ Alternatively, I could consider a measure closer to "physical productivity" (or TFPQ) in Foster, Haltiwanger and Syverson (2008), using firm-level deflators. In that case, I simply divide output and employment at the firm-level to compute firm productivity. Under this definition changes in physical productivity are more tightly connected to actual firm productivity, $z$, so that cross-firm reallocations are more pronounced and firm-entry less important for productivity growth. Other than that, results (available upon request) are consistent with the results of Table VI.
} 
Table VI: Decomposition of overall productivity growth: model simulations for the US

\begin{tabular}{lcc}
\hline Measured Product. & \multicolumn{2}{c}{ Revenue productivity } \\
\hline & Balanced growth & Trade liber. \\
\hline Overall growth & $21.1 \%$ & $22.4 \%$ \\
\hline Decomposition & & \\
Within-firm share & 0.68 & 0.67 \\
Cross-firm share & 0.13 & 0.15 \\
Between-firm share & -0.06 & -0.05 \\
Entry-Exit share & 0.25 & 0.23
\end{tabular}

Note: Data generated by simulating 10,000,000 firms 10 times and reporting the average.

The contribution of continuing firms is itself decomposed into three terms: the within-firm productivity changes with initial weights, the cross-effect of reallocation and productivity changes, and the between-firm effect of reallocating production given initial productivity.

Table VI illustrates this decomposition for the benchmark model in a balanced growth path and under the trade liberalization scenario. The overall productivity growth is explained by the growth of the efficiency frontier of ideas, $g_{E}>0$, and the growth in population, $g_{\eta}>0$, which lead to a reduction in the overall price index. The decomposition for productivity growth is notably close to the empirical decomposition of Foster, Haltiwanger and Krizan (2001) for US manufacturing firms (see their Table 4). In line with their findings a significant component of firm growth is explained by the within- component, though in my case it is about 20 percentage points higher. Cross-firm reallocations are also an important factor, as firms with improvements in their measured productivity also increase their sales. Since in the calibration the mean growth rate is negative, $\mu<0$, the between-firm effect is negative. Because trade liberalization improves productivity relatively little over a ten year period, the decomposition remains roughly invariant.

The dynamic decomposition is consistent with the one of Bernard et al. (2003) but assigns a much larger share to cross-firm reallocation compared to a static model. Dynamic crossfirm reallocations play a key role in which firms gain from trade liberalization but also in understanding the determinants of overall productivity growth.

\section{Conclusion}

This paper presented an analytical unified framework of firm selection and growth. The framework highlights the importance of modeling firm dynamics for trade. Trade liberalization benefits the largest exporters but over a number of years, even after a trade liberalization, there is a substantial drop in market shares. New entrants, despite their small initial 
size eventually gain substantial market share and account for an important part of overall productivity growth.

The framework is based on modeling a market penetration choice-and thus demandat the firm-level. It allows for a parsimonious calibration that nevertheless implies a good fit to the data. The success of this framework suggests that carefully modeling marketing costs could be a promising avenue for a deeper understanding of firm dynamics. Modeling continuing customer relationships, as in Eaton et al. (2012), or adjustment frictions, as in Itskhoki and Helpman (2014) and Cosar, Guner and Tybout (2010), are natural avenues to extend this approach to better understand the transition dynamics of trade liberalizations. 


\section{References}

Abbring, Jaap H. and Jeffrey R. Campbell. 2003. "A Structural Empirical Model of Firm Growth, Learning, and Survival." NBER working paper 9712.

Albornoz, Facundo, Gregory Corcos, Emanuel Ornelas and Hector F. Calvo Pardo. 2009. "Sequential Exporting." mimeo LSE .

Alessandria, George and Horag Choi. 2007. "Establishment Heterogeneity, Exporter Dynamics, and the Effects of Trade Liberalization." Working Paper 07-17, Federal Reserve Bank of Philadelphia

Allen, Treb, Costas Arkolakis and Xiangliang Li. 2014. "On the existence and uniqueness of trade equilibria." mimeo, Northwestern and Yale Universities .

Allen, Treb, Costas Arkolakis and Yuta Takahashi. 2014. "Universal Gravity." mimeo .

Amaral, Luis A. Nunes, Sergey V. Buldyrev, Shlomo Havlin, Heiko Leschhorn, Phillipp Mass, Michael A. Salinger, Eugene Stanley and Michael H.R. Stanley. 1997. "Scaling Behavior in Economics: I. Empirical Results for Company Growth." Journal of Physics 7(4):621-633.

An, Mark Yuying. 1998. "Logconcavity versus Logconvexity: A Complete Characterization." Journal of Economic Theory 80(2):350-369.

Anderson, James E. and Eric Van Wincoop. 2004. "Trade Costs." Journal of Economic Literature 42(3):691-751.

Arellano, Cristina, Yan Bai and Jing Zhang. 2012. "Firm Dynamics and Financial Development." Journal of Monetary Economics 59(6):533-549.

Arkolakis, Costas. 2010. "Market Penetration Costs and the New Consumers Margin in International Trade." Journal of Political Economy 118(6):1151-1199.

Arkolakis, Costas, Arnaud Costinot and Andres Rodríguez-Clare. 2012. "New Trade Models, Same Old Gains?" American Economic Review 102(1):94-130.

Arkolakis, Costas, Arnaud Costinot, Dave Donaldson and Andres Rodríguez-Clare. 2012. "The Elusive Pro-Competitive Effects of Trade." mimeo .

Arkolakis, Costas and Marc-Andreas Muendler. 2010. "The Extensive Margin of Exporting Products: A Firm-Level Analysis." NBER Working Paper 16641.

Arkolakis, Costas, Olga Timoshenko and Theodore Papageorgiou. 2009. "Firm Learning and Growth." mimeo, Yale University .

Arkolakis, Costas, Svetlana Demidova, Peter J Klenow and Andres Rodríguez-Clare. 2008. "Endogenous Variety and the Gains from Trade." American Economic Review, Papers and Proceedings 98(4):444-450.

Atkeson, Andrew and Ariel Burstein. 2010. "Innovation, Firm Dynamics, and International Trade." Journal of Political Economy 118(3):433-489.

Axtell, Rob L. 2001. "Zipf Distribution of U.S. Firm Sizes." Science 293(5536):1818-1820.

Baldwin, Richard and Paul Krugman. 1989. "Persistent Trade Effects of Large Exchange Rate Shocks." Quarterly Journal of Economics 104(4):635-654.

Bastos, Paulo and Daniel Dias. 2012. "The Life Cycle of Exporting Firms." mimeo, University of Illinois, Urbana Champaign.

Bernard, Andew B., Jonathan Eaton, J. Bradford Jensen and Samuel Kortum. 2003. "Plants and Productivity in International Trade." American Economic Review 93(4):1268-1290. 
Bernard, Andrew B, Renzo Massari, Jose-Daniel Reyes and Daria Taglioni. 2014. "Exporter dynamics, firm size and growth, and partial year effects." NBER working paper 19865.

Bernard, Andrew B., Stephen J. Redding and Peter K. Schott. 2009. "Multi-Product Firms and Product Switching." American Economic Review 110(1):70-97.

Birch, David L. 1981. "Who Creates Jobs?" The Public Interest 65:3-14.

Birch, David L. 2010. Job Creation in America: How Our Smallest Companies Put the Most People to Work. New York: Free Press.

Broda, Cristian and David Weinstein. 2006. "Globalization and the Gains from Variety." Quarterly Journal of Economics 121(2):541-585.

Burstein, Ariel and Jonathan Vogel. 2012. "International Trade, Technology, and the Skill Premium.". Manuscript, Columbia University and UCLA.

Cabral, Luis and Jose Mata. 2003. "On the Evolution of the Firm Size Distribution: Facts and Theory." American Economic Review 93(4):1075-1090.

Caves, Richard. 1998. "Industrial Organization and New Findings on the Turnover and Mobility of Firms." Journal of Economic Literature 36(4):1947-1982.

Chaney, Thomas. 2008. "Distorted Gravity: The Intensive and Extensive Margins of International Trade." American Economic Review 98(4):1707-1721.

Comin, Diego and Sunil Mulani. 2007. "A Theory of Growth and Volatility at the Aggregate and Firm Level." mimeo, Harvard University .

Cooley, Thomas F. and Vincenzo Quadrini. 2001. "Financial Markets and Firm Dynamics." American Economic Review 91(5):91.

Cosar, Kerem, Nezih Guner and James Tybout. 2010. "Firm Dynamics, Job Turnover, and Wage Distributions in An Open Economyl." NBER working paper 16326.

Davis, Steven J., John Haltiwanger, Ron Jarmin and Javier Miranda. 2007. "Volatility and Dispersion in Business Growth Rates: Publicly Traded versus Privately Held Firms." 21:107-180.

Davis, Steven J., John Haltiwanger, Ronald S. Jarmin, C. J. Krizan, Javier Miranda, Alfred Nucci and Kristin Sandusky. 2009. Measuring the Dynamics of Young and Small Businesses: Integrating the Employer and Nonemployer Universes. In Producer Dynamics: New Evidence from Micro Data, ed. Timothy Dunne, Bradford J. Jensen and Mark J. Roberts. Chicago, Illinois: NBER pp. 329-368.

Davis, Steven J., John Haltiwanger and Scott Schuh. 1996. "Small Business and Job Creation: Dissecting the Myth and Reassesing the Facts." Small Business Economics 8(4):297-315.

Demidova, Svetlana, Hiau Looi Kee and Kala Krishna. 2006. Do trade policy differences induce sorting? Theory and evidence from Bangladeshi apparel exporters. Technical report National Bureau of Economic Research.

Dixit, Avinash K. and Joseph E. Stiglitz. 1977. "Monopolistic Competition and Optimum Product Diversity." American Economic Review 67(3):297-308.

Dixit, Avinash K. and Robert S. Pindyck. 1994. Investment under Uncertainty. Princeton, New Jersey: Princeton University Press.

Dunne, Timothy, Mark J. Roberts and Larry Samuelson. 1988. "Patterns of Firm Entry and Exit in US Manufacturing Industries." The RAND Journal of Economics 19(4):495-515.

Dunne, Timothy, Mark J. Roberts and Larry Samuelson. 1989. "The Growth and Failure of U.S. Manufacturing Plants." Quarterly Journal of Economics 104(4):671-698. 
Eaton, Jonathan, Marcela Eslava, Cornell J. Krizan, Maurice Kugler and James Tybout. 2012. "A Search and Learning Model of Export Dynamics.". Manuscript, Pennsylvania State University.

Eaton, Jonathan, Marcela Eslava, Maurice Kugler and James Tybout. 2008. The Margins of Entry Into Export Markets: Evidence from Colombia. In Globalization and the Organization of Firms and Markets, ed. Elhanan Helpman, Dalia Marina and Thieery Verdier. Massachusetts: Harvard University Press.

Eaton, Jonathan and Samuel Kortum. 2002. "Technology, Geography and Trade." Econometrica 70(5):1741-1779.

Eaton, Jonathan and Samuel Kortum. 2011. Technology in the Global Economy: A Framework for Quantitative Analysis. Manuscript, Penn State Univesity and Yale University.

Eaton, Jonathan, Samuel Kortum and Francis Kramarz. 2011. "An Anatomy of International Trade: Evidence from French Firms." Econometrica 79(5):1453-1498.

Ericson, Richard and Ariel Pakes. 1998. "Empirical Implications of Alternative Models of Firm Dynamics." Journal of Economic Theory 79(1):1-45.

Evans, David S. $1987 a$. "The Relationship Between Firm Growth, Size, and Age: Estimates for 100 Manufacturing Industries." The Journal of Industrial Economics 35(4):567-581.

Evans, David S. 1987b. "Tests of Alternative Theories of Firm Growth." The Journal of Political Economy 95(4):657-674.

Foster, Lucia, John C Haltiwanger and Cornell John Krizan. 2001. Aggregate productivity growth. Lessons from microeconomic evidence. In New developments in productivity analysis. University of Chicago Press pp. 303-372.

Foster, Lucia, John Haltiwanger and Chad Syverson. 2008. "Reallocation, Firm Turnover, and Efficiency: Selection on Productivity or Profitability?" American Economic Review 98(1):394425.

Foster, Lucia, John Haltiwanger and Chad Syverson. 2010. "The Slow Growth of New Plants: Learning About Demand?" Americn .

Fujii, Daisuke. 2013. "International Trade Dynamics with Sunk Costs and Productivity Shocks." Unpublished manuscript .

Gabaix, Xavier. 1999. "Zipf's Law for Cities: An Explanation." Quarterly Journal of Economics 114(3):739-767.

Gibrat, Robert. 1931. Les Inegalites Economiques; Applications: Aux Inegalites Des Richesses, a la Concentration Des Enterprises, Aux Populations Des Villes, Aux Statistiques Des Familles, Etc. D'une Loi Nouvelle, la Loi de L'effet Proportionnel. Paris: Librairie du Recueil Sirey.

Haltiwanger, John, Ron Jarmin and Javier Miranda. 2011. "Who Creates Jobs? Small Vs. Large Vs. Young." NBER working paper 16300.

Harrison, Michael. 1985. Brownian Motion and Stochastic Flow Systems. New York: John Wiley and Sons.

Heckman, James J. 1979. "Sample Selection Bias as a Specification Error." Econometrica 47(1):153161.

Helpman, Elhanan, Marc J. Melitz and Stephen R. Yeaple. 2004. "Export Versus FDI with Heterogeneous Firms." American Economic Review 94(1):300-316.

Hopenhayn, Hugo A. 1992. "Entry, Exit, and Firm Dynamics in Long Run Equilibrium." Econometrica 60(5):1127-1150. 
Hopenhayn, Hugo and Richard Rogerson. 1993. "Job Turnover and Policy Evaluation: A General Equilibrium Analysis." Journal of Political Economy 101(5):915-938.

Huber, Peter, Harald Oberhofer and Michael Pfaffermayr. 2013. "Who Creates Jobs? Estimating Job Creation Rates at the Firm Level." WIFO Working Paper 435.

Impullitti, Giammario, Alfonso A. Irarrazabal and Luca David Opromolla. 2013. "A Theory of Entry Into and Exit from Export Markets." Journal of International Economics 90(1):75-90.

Irarrazabal, Alfonso A. and Luca David Opromolla. 2009. "The Cross Sectional Dynamics of Heterogeneous Firms Models.". Manuscript, Bank of Portugal.

Itskhoki, Oleg and Elhanan Helpman. 2014. "Firms, Tarde and Labor Market Dynamics." mimeo, Harvard and Princeton .

Jovanovic, Boyan. 1982. "Selection and the Evolution of Industry." Econometrica 50(3):649-670.

Kehoe, Timothy J, Jack M Rossbach and Kim J Ruhl. 2013. "Using the new products margin to predict the industry-level impact of trade reform." NBER working paper 19692.

Kehoe, Timothy J. and Kim J. Ruhl. 2013. "How Important Is the New Goods Margin in International Trade?" Journal of Political Economy 121(2):358 - 392.

Klette, Jacob and Samuel Kortum. 2004. "Innovating Firms and Aggregate Innovation." Journal of Political Economy 112(5):986-1018.

Koren, Miklos and Silvana Tenreyro. 2013. "Technological Diversification." The American Economic Review 103(1):378-414.

Lee, Yoonsoo and Toshihiko Mukoyama. 2008. "Entry, Exit, and Plant-Level Dynamics over the Business Cycle." mimeo University of Virginia .

Lentz, Rasmus and Dale Mortensen. 2008. "An Empirical Model of Growth Through Product Innovation." Econometrica 76(6):1317-1373.

Luttmer, Erzo G. J. 2007. "Selection, Growth, and the Size Distribution of Firms." Quarterly Journal of Economics 122(3):1103-1144.

Luttmer, Erzo G. J. 2011. "On the Mechanics of Firm Growth." The Review of Economic Studies 78(3):1042-1068.

Mansfield, E. 1962. "Entry, Gibrat's Law, Innovation, and the Growth of Firms." American Economic Review 52(5):1023-1051.

Martins, Joaquim Oliveira, Stefano Scarpetta and Dirk Pilat. 1996. "Mark-Up Ratios in Manufacturing Industries: Estimates for 14 OECD Countries." OECD Economics Department Working Paper 162.

Melitz, Marc J. 2003. "The Impact of Trade on Intra-Industry Reallocations and Aggregate Industry Productivity." Econometrica 71(6):1695-1725.

Melitz, Marc J. and Gianmarco I. P. Ottaviano. 2008. "Market Size, Trade, and Productivity." The Review of Economic Studies 75(1):295-316.

Molina, Danielken and Marc-Andreas Muendler. 2008. "Preparing to Export.". Manuscript, University of California-San Diego.

Moscarini, Giuseppe. 2005. "Job Matching and the Wage Distribution." Econometrica 73(2):481516. 
Neumark, David, Brandon Wall and Junfu Zhang. 2011. "Do Small Businesses Create More Jobs? New Evidence for the United States from the National Establishment Time Series." The Review of Economics and Statistics 93(1):16-29.

Nualart, David. 2006. The Malliavin calculus and related topics. Springer.

Papageorgiou, Theodore. 2014. "Learning Your Comparative Advantages." Journal of International Economics 81(3):1263-1295.

Pozzi, Andrea and Fabiano Schivardi. 2012. Demand or productivity: What determines firm growth? Centre for Economic Policy Research.

Reed, William J. 2001. "The Pareto, Zipf and Other Power Laws." Economics Letters 74(1):15-19.

Reed, William J. 2002. "On the Rank-Size Distribution for Human Settlements." Journal of Regional Science 42(1):1-17.

Rossi-Hansberg, Esteban and Mark L. J. Wright. 2007. "Establishment Size Dynamics in the Aggregate Economy." American Economic Review 97(5):1639-1666.

Ruhl, Kim J. and Jonathan Willis. 2008. "New Exporter Dynamics.". Manuscript New York University.

Sampford, M. P. 1953. "Some Inequalities on Mill's Ratio and Related Function." The Annals of Mathematical Statistics 24(1):130-132.

Simon, Herbert A. 1955. "On a Class of Skew Distribution Functions." Biometrika 42(3/4):425-440.

Sutton, John. 1997. "Gibrat's Legacy.” Journal of Economics Literature 35(1):40-59.

Sutton, John. 2002. "The Variance of Firm Growth Rates: 'The Scaling Puzzle'." Physica A $312(3): 577-590$.

Timoshenko, Olga. 2012. "Product Switching in a Model of Learning." mimeo, George Washington University .

Yule, Udny. 1925. "A Mathematical Theory of Evolution, Based on the Conclusions of Dr. J. C. Willis, F.R.S." Philosophical Transacions of the Royal Society of London 213:21-87. 
Figure A.I: Distribution of sales: total sales of US manufacturing census firms and domestic sales of French manufacturing firms

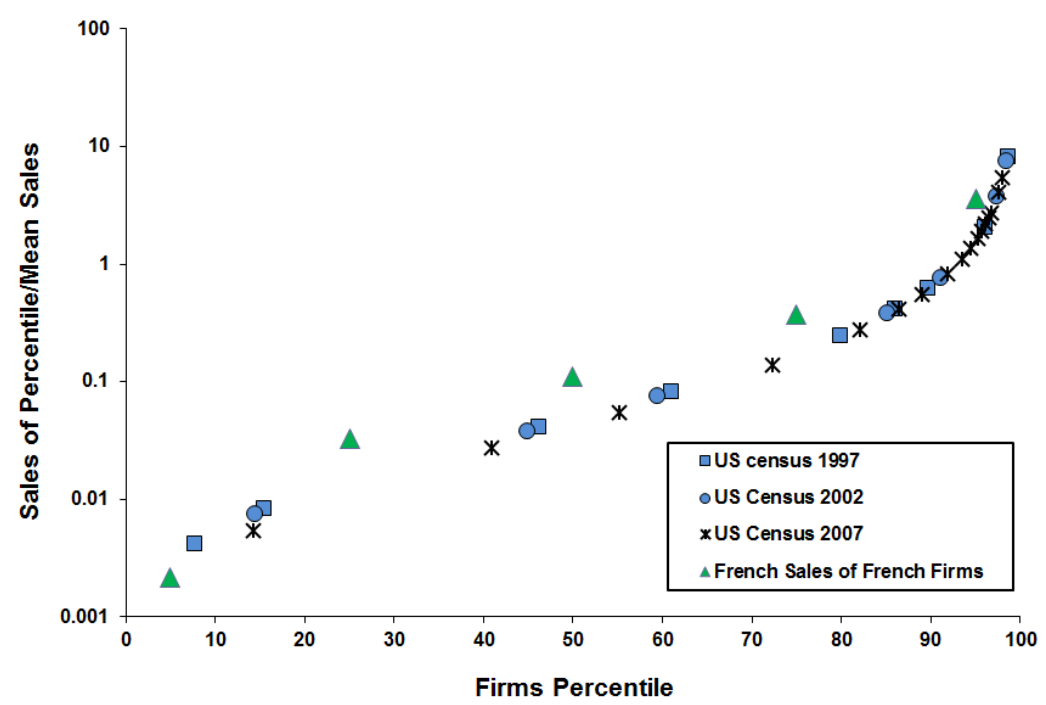

Note: See Figure II for details on the US data; French data from Eaton, Kortum and Kramarz (2011)

\section{A Data Appendix}

Distribution of Sales The distribution of sales of US manufacturing firms and the one of French manufacturing firms in France are displayed in Figure A.I. The two distributions exhibit remarkable similarity, and similar pattern has been reported in a number of datasets, including the exporting data for Brazilian exporters (see Arkolakis and Muendler (2010) for Brazil).

Distribution of Growth Rates Figure A.II plots the probability density of growth rates for deciles of initial firm sizes. The distributions of growth rates change progressively from a very skewed distribution (decile 1) to a distribution that approximates a shifted lognormal (decile 10).

\section{B Model Appendix}

\section{B.1 The O-U process}

Let $s_{a}=\ln \tilde{z}_{a}$. Ignoring the aggregate technology shock and the initial level of productivity the $\mathrm{O}-\mathrm{U}$ process can be written as

$$
s_{a}=g_{I} a+\mu\left(1-e^{-\rho a}\right)+e^{-\rho a} s_{0}+\sigma e^{-\rho a} \int_{0}^{a} e^{\rho s} d W_{s} .
$$

(To derive this expression, multiply both sides by $e^{\rho a}$, differentiate with respect to $a$ and then integrate to obtain the equivalent definition of $s_{a}$ that is given in equation 5). By rearranging 
Figure A.II: Density of growth rates and size deciles: Brazilian exporters in the US

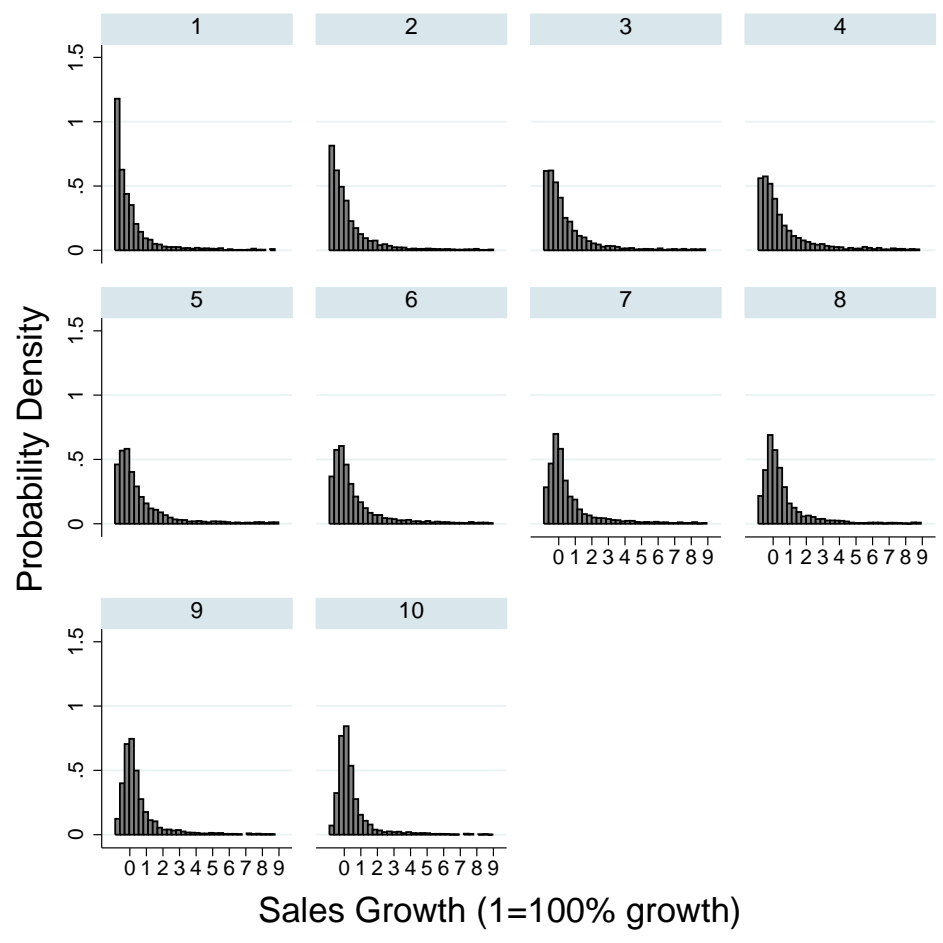

Note: See Figure V for details of the Brazilian data. 
terms,

$$
\begin{gathered}
s_{a}=e^{-\rho}\left(e^{\rho}-1\right) \mu+\left(g_{I}-g_{E}\right)+ \\
e^{-\rho}\left[\mu\left(1-e^{-\rho(a-1)}\right)+S_{0} e^{-\rho(a-1)}+\sigma\left(e^{-\rho(a-1)} \int_{0}^{a-1} e^{\rho s} d W_{s}\right)+\frac{\left(g_{I}-g_{E}\right)(a-1)}{e^{-\rho}}\right] \\
+e^{-\rho} \sigma e^{-\rho(a-1)} \int_{a-1}^{a} e^{\rho s} d W_{s},
\end{gathered}
$$

and using the above expression and a change of variables in the integral

$$
s_{a}=\left(g_{I}-g_{E}\right)+\left(1-e^{-\rho}\right) \mu+e^{-\rho} s_{a-1}+\sigma \int_{0}^{1} e^{\rho(z-1)} d W_{z},
$$

so that the $\mathrm{O}-\mathrm{U}$ process is the continuous time analog of an $\mathrm{AR}(1)$ process with autoregressive coefficient $e^{-\rho}$.

\section{B.2 Proof of Proposition 1}

Part (i) To prove that there exists a pdf $f_{i}(z, a)$ for random variable $z$, it is equivalent to prove the existence of a pdf of $\ln \tilde{z}_{a}$. Theorem 2.3.2 in page 111 of Nualart (2006) states that if Hormander's condition holds for a Stratonovich integral,

$$
X_{t}=X_{0}+\int_{0}^{t} \mu\left(X_{s}\right) d s+\int_{0}^{t} \sigma\left(X_{s}\right) \circ d W_{s}
$$

then the distribution function of $X_{t}$ is absolutely continuous (there exists a pdf). The Hormander condition for a Stratonovich integral is $\sigma(x)^{2}+\left(\mu(x)^{\prime} \sigma(x)-\mu(x) \sigma^{\prime}(x)\right)^{2} \neq 0$. In this paper and in many economic contexts, the stochastic process is in an Ito integral form and, thus, to complete part (i) this condition has to be transformed for that case. Since the equivalent statement of an Ito integral in the Stratonovich integral form is

$$
\begin{aligned}
X_{t} & =X_{0}+\int_{0}^{t} g\left(X_{s}\right) d s+\int_{0}^{t} \sigma\left(X_{s}\right) d W_{s} \\
& =X_{0}+\int_{0}^{t}\left(g\left(X_{s}\right)-\frac{1}{2} \sigma^{\prime}\left(X_{s}\right) \sigma\left(X_{s}\right)\right) d s+\int_{0}^{t} \sigma\left(X_{s}\right) \circ d W_{s},
\end{aligned}
$$

the Hormander's condition in the Ito integral context is that $\sigma(x)$ and $\left[g(x)-\frac{1}{2} \sigma^{\prime}(x) \sigma(x)\right]^{\prime} \sigma(x)-\left[g(x)-\frac{1}{2} \sigma^{\prime}(x) \sigma(x)\right] \sigma^{\prime}(x)=g^{\prime}(x) \sigma(x)-\frac{1}{2} \sigma^{\prime \prime}(x) \sigma(x)^{2}-g(x) \sigma^{\prime}(x)$, cannot be zero at the same time, which is equivalent to saying that $\sigma(x)^{2}+\left(g(x) \sigma^{\prime}(x)\right)^{2} \neq 0$ i.e., A1.

Furthermore, Theorem 2.3.3 of Nualart (2006) states that using the Hormander's condition and assuming that $g\left(X_{s}\right), \sigma\left(X_{s}\right)$, have bounded derivatives of all orders, imply that $X_{t}$ 's density is a smooth function (i.e., infinitely differentiable and thus, of course, continuous).

Part (ii) The distribution function of all ideas can be expressed by

$$
F(z)=\int_{0}^{\infty} g_{B} e^{-g_{B} a}\left(\int_{0}^{z} f(x, a) d x\right) d a .
$$


According to Tonelli's theorem, the sequence of this integral can be exchanged, so that

$$
F(z)=\int_{-\infty}^{z}\left(\int_{0}^{\infty} g_{B} e^{-g_{B} a} f(x, a) d a\right) d x=\int_{-\infty}^{z} f(x) d x .
$$

To prove that is finite, let the set $A \equiv\{z \mid f(z)=\infty\}$. The measure of $A$ must be zero. Suppose not, mes $(A)=\epsilon>0$, then $\int_{A} f(z) d x=\infty$, which is a contradiction with $\int_{-\infty}^{\infty} f(z) d x=1<\infty$ completing the proof of part (ii).

\section{B.3 Deriving the Stationary Distribution of Productivities}

I derive the distribution of productivities of ideas, equation (16), using the Kolmogorov equation (19) and the conditions (20)-(22). A simple guess for the solution of this equation is $f(z)=A_{1} z^{\theta_{1}-1}+A_{2} z^{-\theta_{2}-1}$ where $\theta_{1}$ and $-\theta_{2}$ are, respectively, the positive and negative solutions of the quadratic equation $\frac{1}{2} \sigma_{I}^{2} \theta_{i}^{2}-\mu \theta_{i}-g_{B}=0, i=1,2$, given by (17) and (18). Given this guess, the requirement that $f_{i}(z)$ is a probability density-condition (21)-implies $A_{2}=0$ for $z<\bar{z}_{i}$ and $A_{1}=0$ for $z>\bar{z}_{i}$.

To derive equation (16), I compute the value of $A_{1}$ for $z<\bar{z}_{i}$ and $A_{2}$ for $z \geq \bar{z}_{i}$. Equation (22), characterizes the flows at the entry point,

and which with (21) gives

$$
\frac{1}{2} \sigma_{I}^{2}\left(A_{1} \theta_{1} \bar{z}_{i}^{\theta_{1}}+A_{2} \theta_{2} \bar{z}_{i}^{-\theta_{2}}\right)=g_{B},
$$

$$
\int_{0}^{\bar{z}_{i}} A_{1} z^{\theta_{1}-1} d s+\int_{\bar{z}_{i}}^{+\infty} A_{2} z^{-\theta_{2}-1} d s=1 .
$$

The definitions of $\theta_{1}, \theta_{2}$ imply that the solution is $A_{1}=\bar{z}^{-\theta_{1}} \theta_{1} \theta_{2} /\left(\theta_{1}+\theta_{2}\right)$ and $A_{2}=$ $\bar{z}^{-\theta_{2}} \theta_{1} \theta_{2} /\left(\theta_{1}+\theta_{2}\right)$.

Notice that the solutions also satisfy the first term in the left-hand side of (22) since they imply that $f\left(\bar{s}_{i}-\right)=f\left(\bar{s}_{i}+\right)$. In other words the distribution is continuous, but the derivative has a kink at $\bar{s}_{i}$.

\section{B.4 Exit Rates and Firm Sales}

In the following proofs and derivations, I am going to use a number of definitions and well known facts of the Normal distribution. Recall that the pdf of the standard normal distribution with mean 0 and variance 1 is given by $\varphi(x)=\frac{e^{-x^{2}} / 2}{\sqrt{2 \pi}}$ and the cumulative distribution function (cdf) by $\Phi\left(\frac{x-\mu}{\sigma_{I}}\right)=\frac{1}{\sigma_{I} \sqrt{2 \pi}} \int_{-\infty}^{x} e^{-(\tilde{x}-\mu)^{2} / 2 \sigma_{I}^{2}} d \tilde{x}$.

Property 1 (P1). The error function is defined by: $\operatorname{erf}(x)=\frac{2}{\sqrt{\pi}} \int_{0}^{x} e^{-(\tilde{x})^{2}} d \tilde{x}$.

Property $2(\mathbf{P} 2) . \Phi(x)=\frac{1}{2}\left[1+\operatorname{erf}\left(\frac{x}{\sqrt{2}}\right)\right]$, where $\Phi(x)$ is the cdf of the standard normal $c d f$. 
Property 3 (P3). $\int e^{-\tilde{c}_{1} x^{2}+\tilde{c}_{2} x} d x=e^{\left(\tilde{c}_{2}\right)^{2} / 4\left(\tilde{c}_{1}\right)} \sqrt{\pi} \operatorname{erf}\left(\frac{2 \tilde{c}_{1} x-\tilde{c}_{2}}{2 \sqrt{\tilde{c}_{1}}}\right) /\left(2 \sqrt{\tilde{c}_{1}}\right)$, for some constants $\tilde{c}_{1}, \tilde{c}_{2}>0$.

Firm Survival in a market The main objective is to compute the probability that a firm will be selling in a market after $a$ years (so that $s_{i j a} \geq 0$ ), conditional on the initial productivity of the firm today, $s_{i j 0}=s_{0}$. I denote this probability by $S\left(a \mid s_{0}\right)$ and using expression (15), it is given by

$$
S\left(a \mid s_{0}\right)=\int_{0}^{+\infty} \frac{e^{-\left(\frac{s_{a}-s_{0}-\mu a}{\sigma_{I} \sqrt{a}}\right)^{2} / 2}}{\sigma_{I} \sqrt{a 2 \pi}} d s_{a} .
$$

Using a change of variables yields equation (28) in the main text.

Cohort Survival Rates I derive expression (29): the probability that a firm in an incumbent cohort, among all the currently operating firms, $s_{i j 0} \geq 0$, also operates after time $a$ has elapsed, $s_{i j a} \geq 0$. If I denote this probability as $\operatorname{Pr}\left(s_{i j a} \geq 0 \mid s_{i j 0} \geq 0\right)$, then the cohort survival rate is $S_{i j}(a)=\operatorname{Pr}\left(s_{i j a} \geq 0 \mid s_{i j 0} \geq 0\right)$. Then,

$$
\begin{gathered}
\operatorname{Pr}\left(s_{i j a} \geq 0 \mid s_{i j 0} \geq 0\right)=\int_{0}^{+\infty} \int_{0}^{+\infty} \operatorname{Pr}\left(s_{i j a}=s_{a} \mid s_{i j 0}=s_{0}\right) \frac{\operatorname{Pr}\left(s_{i j 0}=s_{0}\right)}{\operatorname{Pr}\left(s_{i j 0} \geq 0\right)} d s_{a} d s_{0} \\
=\int_{0}^{+\infty} \frac{\operatorname{Pr}\left(s_{i j 0}=s_{0}\right)}{\operatorname{Pr}\left(s_{i j 0} \geq 0\right)} \int_{0}^{+\infty} \operatorname{Pr}\left(s_{i j a}=s_{a} \mid s_{i j 0}=s_{0}\right) d s_{a} d s_{0} .
\end{gathered}
$$

The conditional density of productivities is given by

$$
\frac{\operatorname{Pr}\left(s_{i j 0}=s_{0}\right)}{\operatorname{Pr}\left(s_{i j 0} \geq 0\right)}=\theta_{2} e^{-\theta_{2}\left(s_{0}-0\right)}
$$

The inner integral of expression (33) is given by equation (28). Thus, by replacing expressions (28) and (34) in (33), and using integration by parts,

$$
\operatorname{Pr}\left(s_{i j a} \geq 0 \mid s_{i j 0} \geq 0\right)=\Phi\left(\frac{\mu \sqrt{a}}{\sigma_{I}}\right)+\int_{0}^{+\infty} e^{-\theta_{2} s_{0}} \frac{1}{\sigma_{I} \sqrt{a}} \varphi\left(\frac{s_{0}+\mu a}{\sigma_{I} \sqrt{a}}\right) d s_{0} .
$$

Using the definition of the error function, P1, and P3 the integral of the last expression becomes

$$
\frac{e^{-\frac{1}{2} \frac{\mu^{2}}{\sigma_{I}^{2}} a}}{\sigma_{I} \sqrt{a 2 \pi}}\left|\frac{e^{\frac{\left(\frac{\mu}{\sigma_{I}^{2}}+\theta_{2}\right)^{2}}{4 \frac{1}{2 \sigma_{I}^{2} a}}} \sqrt{\pi}}{\sqrt{2 \frac{1}{2 \sigma_{I}^{2} a}}} \operatorname{erf}\left(\frac{2 \frac{1}{2 \sigma_{I}^{2} a} x+\frac{\mu}{\sigma_{I}^{2}}+\theta_{2}}{2 \sqrt{\frac{1}{2 \sigma_{I}^{2} a}}}\right)\right|_{x=0}^{x=+\infty}=e^{\frac{\sigma_{I}^{2} a}{2}\left(\theta_{2}\right)^{2}+\theta_{2} \mu a} \Phi\left(-\left(\frac{\mu}{\sigma_{I}}+\theta_{2} \sigma_{I}\right) \sqrt{a}\right),
$$

where for the last equality I used P2 . Combining the expressions gives the survival function, $S_{i j}(a)$, expression (29).

In the online appendix, I show that $S_{i j}(a)$ is increasing in $\mu$, and if $\mu<0, S_{i j}(a)$ is decreasing in $a, D S_{i j}(a)<0$. These results arise because of the properties of the normal distribution.

Expected Log Sales I now sketch the derivations for the expected growth rate of the $\log$ firm sales and its variance that were discussed in section 3.2.1. I derive moments of the 
natural logarithm of sales of the firm after time $a$ has elapsed for $\beta \rightarrow 0$, and get

$$
\ln L_{j \tilde{t}+a}^{\alpha} y_{j \tilde{t}+a} \frac{1}{\tilde{\psi}}+(\sigma-1) s_{i j \tilde{t}+a} .
$$

The first term is deterministic, making derivations straightforward. To compute the moments of the second term, I must derive its moment generating function (MGF). I begin by computing the MGF of some variable $\tilde{s}_{a}$ that is normally distributed with mean $\tilde{\mu}$, variance $\tilde{\sigma}^{2}$. Its lower threshold is $\tilde{x}$ the values of which I will specify below. The MGF is (for some $\tilde{c} \in R)$

$$
\begin{gathered}
E\left(e^{\tilde{c} s_{a}} \mid s_{0}, s_{a} \geq 0\right)=\frac{1}{\tilde{\sigma} \sqrt{2 \pi}} \frac{\int_{\tilde{x}}^{\infty} e^{\tilde{c} x} e^{-\frac{1}{2}\left(\frac{x-\tilde{\mu}}{\tilde{\sigma}}\right)^{2}} d x}{1-\Phi\left(\frac{\tilde{x}-\tilde{\mu}}{\tilde{\sigma}}\right)} \\
=e^{-\frac{(\tilde{\mu})^{2}-\left[(\tilde{\sigma})^{2} \tilde{c}+\tilde{\mu}\right]^{2}}{2(\tilde{\sigma})^{2}}} \frac{\int_{\tilde{x}}^{\infty} \frac{1}{\tilde{\sigma} \sqrt{2 \pi}} e^{-\frac{\left[x-(\tilde{\sigma})^{2} \tilde{\tilde{c}}-\tilde{\mu}\right]^{2}}{2(\tilde{\sigma})^{2}}} d x}{1-\Phi\left(\frac{\tilde{x}-\tilde{\mu}}{\tilde{\sigma}}\right)}=e^{\tilde{\tilde{\mu} \tilde{c}+\frac{\tilde{\sigma}^{2} \tilde{c}^{2}}{2}}} \frac{1-\Phi\left(\frac{\tilde{x}-\tilde{\mu}-\tilde{\sigma}^{2} \tilde{c}}{\tilde{\sigma}}\right)}{1-\Phi\left(\frac{\tilde{x}-\tilde{\mu}}{\tilde{\sigma}}\right)} .
\end{gathered}
$$

In the last equality, I used the definition of the cdf of the normal distribution. I can now adjust the parameters of the distribution so that they correspond to the current firm sales size and the underlying stochastic process: $\tilde{\mu}=(\sigma-1) s_{0}+(\sigma-1) \mu a, \tilde{\sigma}=(\sigma-1) \sigma_{I} \sqrt{a}$, $\tilde{x}=0$. Finally, the moments of the second term of equation (35) can be computed by taking the successive derivatives of the MGF with respect to $\tilde{c}$.

\section{B.5 Proofs of Propositions 4 and 5}

Proof of Proposition 4 The proposition requires that $\partial\left(\mu \frac{h^{\prime}(s)}{h(s)}+\frac{\sigma_{I}^{2}}{2} \frac{h^{\prime \prime}(s)}{h(s)}\right) / \partial s \leq 0$. Extended derivations for this proposition, given in the online appendix, imply that it is equivalent to show that

$$
\mu(\sigma-1)[(1-\tilde{\beta}) / \tilde{\beta}] e^{-s \frac{(\sigma-1)}{\beta}}+\frac{\sigma_{I}^{2}}{2}(\sigma-1)^{2}\left[\left(1-\tilde{\beta}^{2}\right) / \tilde{\beta}^{2}\right] e^{-s \frac{(\sigma-1)}{\beta}} \leq 0 .
$$

Thus, for $\tilde{\beta}=\beta /(\beta-1)$, I need to show that (notice that $e^{s \frac{(\sigma-1)}{\beta}} \geq 1$, for $s \geq 0$ )

$$
-(\tilde{\beta})^{2}\left[\mu(\sigma-1)+(\sigma-1)^{2} \frac{\sigma_{I}^{2}}{2}\right]+\mu(\sigma-1) \tilde{\beta}+(\sigma-1)^{2} \frac{\sigma_{I}^{2}}{2} \leq 0 .
$$

After some manipulations, this expression implies the condition in equation (32). Notice that if $\mu(\sigma-1)+(\sigma-1)^{2} \sigma_{I}^{2}<0$, there does not exist a $\beta \in[0,+\infty)$ that satisfies the inequality.

Proof of Proposition 5 The proof of the proposition uses Ito's Lemma. In particular, the variance of the instantaneous growth rate is given by the square of the second bracketed term in expression (30). Given (31) this term is equal to $\sigma_{I}^{2}(\sigma-1)^{2}$ as $\beta \rightarrow 0$. The second part of the proposition is also straightforward. Given $\beta>0$, the derivative of the term is always negative. Thus, the firm instantaneous variance of growth of sales in a destination is inversely related its size there. In the limit as $s_{i j 0} \rightarrow+\infty$, the term tends to $\sigma_{I}^{2}(\sigma-1)^{2}$, completing the proof of this proposition. 
Table A.I: Entrants and Exiters average size relative to average size of all firms

\begin{tabular}{lcccccc}
\hline Statistics/Census Year & 1963 & 1967 & 1972 & 1977 & 1982 & mean \\
\hline Entrants Relative Size & - & 0.352 & 0.396 & 0.308 & 0.346 & 0.350 \\
Exiters Relative Size & 0.353 & 0.399 & 0.338 & 0.351 & - & 0.360
\end{tabular}

Source: Numbers calculated using market shares (Table 2) and exit rates (Table 8) from DRS.

\section{B.6 Entrants/Exiters Sizes and Sunk Costs}

Table A.I shows the average size of entrants and exiters for 4 cohorts in the US manufacturing census data taken from Dunne, Roberts and Samuelson (1988). The average size of entrants and exiters is practically the same. Similar results are also obtained in the Brazilian exporting and the Colombian exporting data in Eaton et al. (2008).

I consider different calibrations of the sunk cost model and the implied difference for the size of entrants and exiters. I use equation (19) in Luttmer (2007) and perform the following exercise: I consider the average difference of exiters to entrants that will imply a 5-year exit rate of $60 \%$ for the entry cohort (as in the US manufacturing data). For the parameters of benchmark calibration, this model implies that the average size of entrants is around $22 \%$ higher than the size of exiters, whereas with the calibration of Luttmer, this difference is around 25\%. If I use in calibration all parameters as in Luttmer but choose a lower $\sigma=6.55$ (instead of his choice of $\sigma=10$ ) the average size difference is at around $15 \%$, which is still much larger than zero, albeit lower.

\section{B.7 Calibration}

In this subsection, I illustrate how the calibrated model predicts the entire profile of exit and average sales in the data of Dunne, Roberts and Samuelson (1988). The model matches the exit profile of incumbent and new cohorts, as discussed in the main text. Table A.II compares averages across cohorts in the data and model simulations.

I also present evidence from Dunne, Roberts and Samuelson (1988) for the market shares of incumbent cohorts in order to shed light to the patterns of firm growth. Table A.II presents the market shares of surviving firms from incumbent cohorts. Even though there is substantial attrition of incumbent firms and new entrants the average size of incumbentcohort firms increases to around 3.2 times the size of all firms in the span of 15 years. As a result the market shares of the incumbent cohorts is still about $2 / 3$ after 15 years.

I compare the predictions of the endogenous cost benchmark and fixed cost models for average sales of surviving firms to the averages across cohorts in the data presented Table A.II. The benchmark model can match the small contribution of the entry cohorts and 
Table A.II: Cohort exit rates and average sizes: Data and model

\begin{tabular}{llccc}
\hline Statistic / Cohort year & 0 & 5 & 10 & 15 \\
\hline Entry cohort exit rate & & & & \\
Data (mean '67-'77 cohorts) & 0.00 & 0.62 & 0.79 & 0.88 \\
Model & 0.00 & 0.63 & 0.80 & 0.88 \\
Inc. cohort exit rate & & & & \\
Data (mean '67-'77 cohorts) & 0.00 & 0.48 & 0.65 & 0.76 \\
Model & 0.00 & 0.47 & 0.67 & 0.79 \\
Inc. cohort market shares & & & & \\
Data (mean '67-'77 cohorts) & 1.00 & 0.83 & 0.73 & 0.63 \\
Model ( $\beta>0)$ & 1.00 & 0.86 & 0.74 & 0.62 \\
Model $(\beta=0)$ & 1.00 & 0.76 & 0.59 & 0.47
\end{tabular}

Source: Data from Dunne, Roberts, and Samuelson (1988) and model simulations. Mean sales are constructed using data from Dunne, Roberts and Samuelson (1988) for the 1967, 1972, and 1977 censuses using exit rates and market shares. Approximation error appears due to this construction and the fact that numbers represent means across 4-digit industries.

correctly predicts the market share of surviving incumbent firms for up to 15 years. The fixed cost model systematically underpredicts the market shares of incumbent firms.

\section{B.8 Variance of Sales}

I delve deeper into the predictions of the model regarding the growth-size relationship by looking at the variance of firm growth. To contrast the predictions of the different versions of the model, I plot the variance of growth of firms as a function of their initial size percentile in the left panel Figure A.III. Starting with the fixed cost model the variance of firm growth is increasing with size, and is entirely driven by the effects of selection. The volatility of the marketing choice generates an increasing variance of growth-size relationship that dominates the small effects of selection.

In the right panel of Figure A.III, I also illustrate the quantitative predictions of the model regarding the variance of growth rates by using available moments for publicly traded US manufacturing firms, as analyzed by Amaral et al. (1997), and tabulated by employment bins (1-10 employees, 10-100 etc). In general, the endogenous cost model overpredicts the variance of growth rates observed in the data (except for the size bin of 10-100 employees), but captures the inverse relationship of variance of firm growth and firm size. The fixed cost model predicts a (slightly) increasing relationship. Notice that neither model can capture the (roughly) log-linear relationship between variance of growth rates and firm size. Instead, the variance converges eventually to a constant in both models. This log-linear relationship is the topic of discussion in Sutton (2002). 
Figure A.III: Standard deviation of firm growth and initial firm size

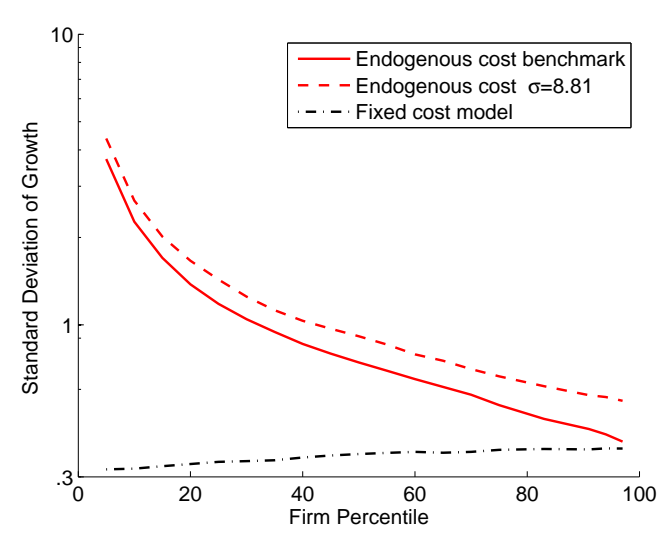

Firm size percentile

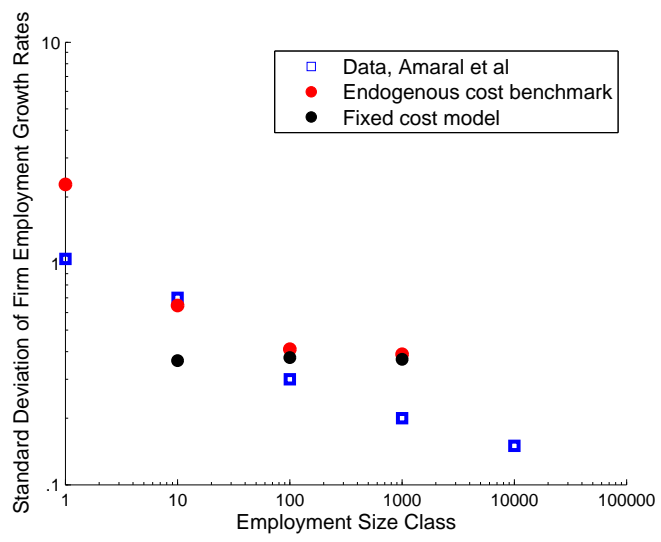

Employment size class

Note: Model data generated by simulating 10,000,000 firms and computing the variance of the growth of one year sales across different firm percentiles. Data by Amaral et al. (1997) are for US Manufacturing firms in COMPUSTAT.

\section{B.9 Application: The Size-Growth Debate}

Do small firms grow faster? This question has been at the center of academic and policy debates over the past three decades. The comprehensive econometric analysis by Evans $(1987 a, b)$ shows that the negative growth-size relationship is robust to correcting for sample truncation caused by the exit of smaller firms. Methodologically, Davis, Haltiwanger and Schuh (1996) and Haltiwanger, Jarmin and Miranda (2011) challenge the inverse size-growth relationship on the basis of the interaction of size classification and possible regression to the mean. This interaction may create a tendency of firms that experience a growth shock in one period to experience an opposite shock in the next one. Haltiwanger, Jarmin and Miranda (2011) propose an alternative measurement of firm growth by considering initial year firm size as its average size in the initial and final periods. They find that with growth computed as final size divided by average size the growth relationship disappears in many of their specifications.

In line with the findings of Neumark, Wall and Zhang (2011), I argue that this alternative measurement is not the appropriate metric of growth. In particular, as I argued, small firms grow faster in the calibrated endogenous cost model. However, when I use the metric of growth proposed by Davis, Haltiwanger and Schuh (1996), the inverse size growth relationship disappears. In particular, in Figure A.IV, I report the growth rates on the simulation for the benchmark calibration of the endogenous cost model. Whereas, the standard metric of growth implies an inverse relationship between firm growth and initial size, consistent with 
Figure A.IV: Survivor growth rates and firm size: Endogenous cost benchmark with initial size or average size

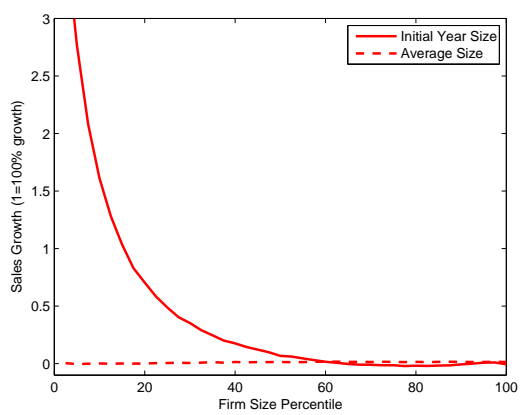

Note: Model data generated by simulating 10,000,000 firms. Growth rates are computed as final firm size divided by initial year size or by the average of initial and final size.

the theoretical predictions of the model and the observed distribution of growth rates, the average size metric of Davis, Haltiwanger and Schuh (1996) implies no relationship (in fact, measured growth rates across categories are slightly increasing). The reason is that their metric of growth classifies all the small firms that grow fast as large creating, as a result, a different kind of misclassification bias . 